\title{
Molten Salt Reactor Signatures and Modeling Study
}

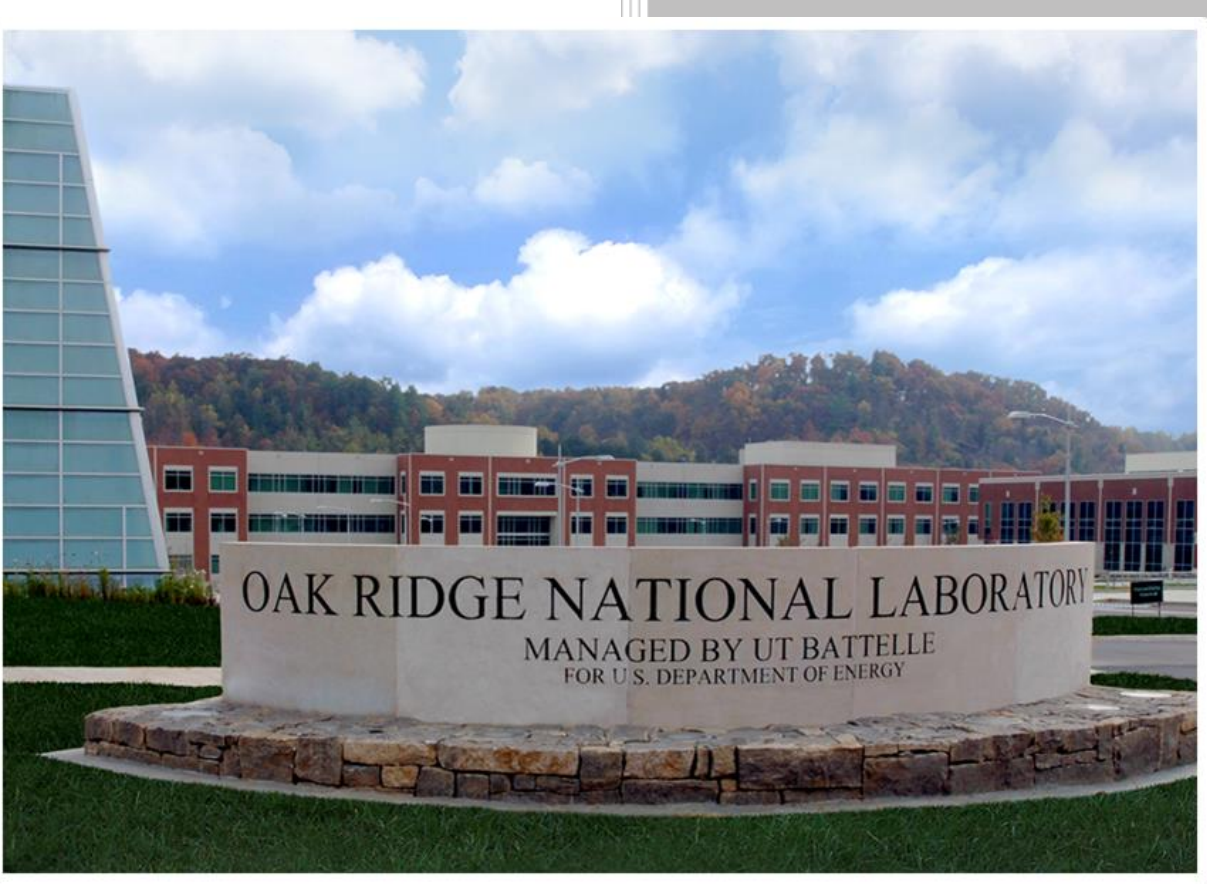

\section{Approved for public release.} Distribution is unlimited.

Michael P. Dion Louise G. Worrall Stephen Croft Logan M. Scott

Nov 18, 2020 


\title{
DOCUMENT AVAILABILITY
}

Reports produced after January 1, 1996, are generally available free via US Department of Energy (DOE) SciTech Connect.

Website www.osti.gov

Reports produced before January 1, 1996, may be purchased by members of the public from the following source:

\author{
National Technical Information Service \\ 5285 Port Royal Road \\ Springfield, VA 22161 \\ Telephone 703-605-6000 (1-800-553-6847) \\ TDD 703-487-4639 \\ Fax 703-605-6900 \\ E-mail info@ntis.gov \\ Website http://classic.ntis.gov/
}

Reports are available to DOE employees, DOE contractors, Energy Technology Data Exchange representatives, and International Nuclear Information System representatives from the following source:

Office of Scientific and Technical Information

PO Box 62

Oak Ridge, TN 37831

Telephone 865-576-8401

Fax 865-576-5728

E-mail reports@osti.gov

Website http://www.osti.gov/contact.html

This report was prepared as an account of work sponsored by an agency of the United States Government. Neither the United States Government nor any agency thereof, nor any of their employees, makes any warranty, express or implied, or assumes any legal liability or responsibility for the accuracy, completeness, or usefulness of any information, apparatus, product, or process disclosed, or represents that its use would not infringe privately owned rights. Reference herein to any specific commercial product, process, or service by trade name, trademark, manufacturer, or otherwise, does not necessarily constitute or imply its endorsement, recommendation, or favoring by the United States Government or any agency thereof. The views and opinions of authors expressed herein do not necessarily state or reflect those of the United States Government or any agency thereof. 


\title{
MOLTEN SALT REACTOR SIGNATURES AND MODELING STUDY
}

\author{
Michael P. Dion \\ Louise G. Worrall \\ Stephen Croft \\ Logan M. Scott
}

Date Published:

Nov 18, 2020

\author{
Prepared by \\ OAK RIDGE NATIONAL LABORATORY \\ Oak Ridge, TN 37831-6283 \\ managed by \\ UT-BATTELLE, LLC \\ for the \\ US DEPARTMENT OF ENERGY \\ under contract DE-AC05-00OR22725
}





\section{CONTENTS}

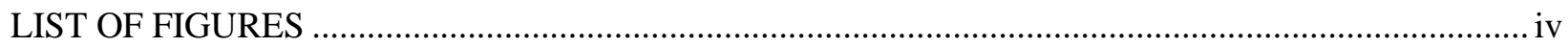

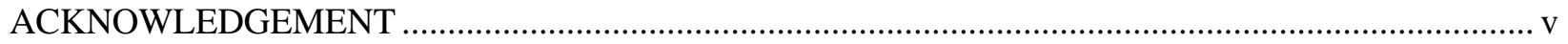

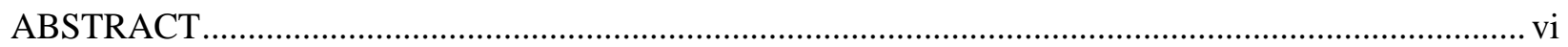

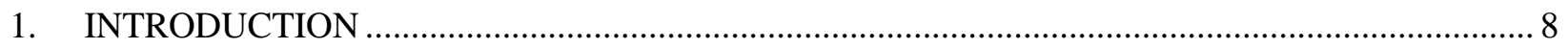

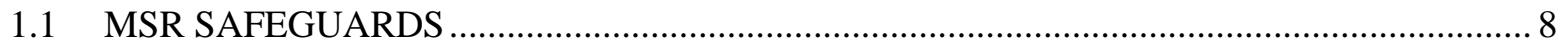

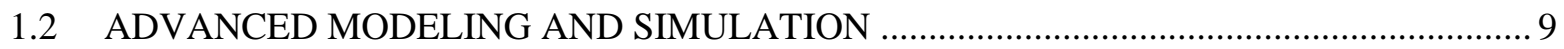

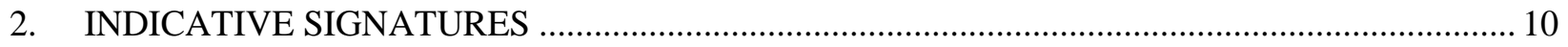

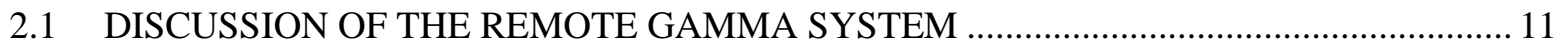

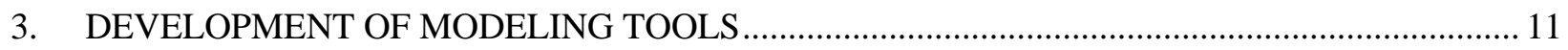

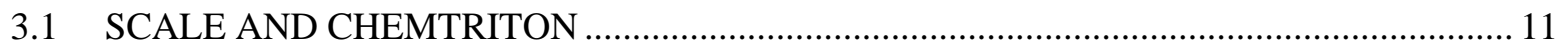

3.2 TRANSIENT SIMULATION FRAMEWORK OF RECONFIGURABLE MODELS

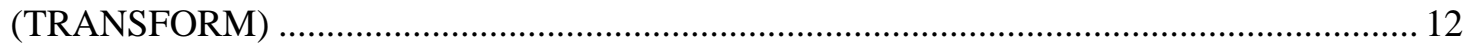

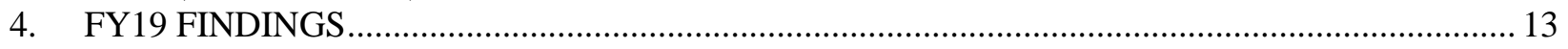

4.1 SIMULATIONS WITH SCALE/TRITON ................................................................... 14

4.2 PERTURBED INVENTORY CALCULATIONS - TRANSIENTS …................................. 15

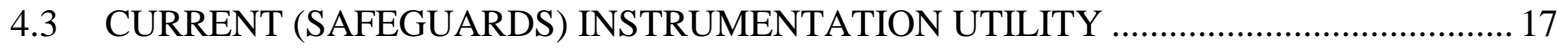

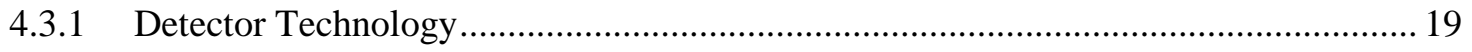

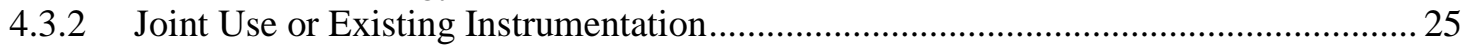

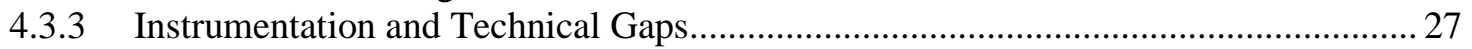

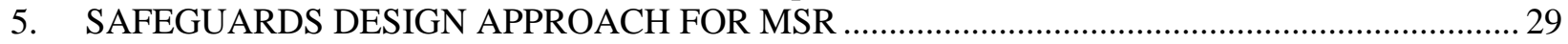

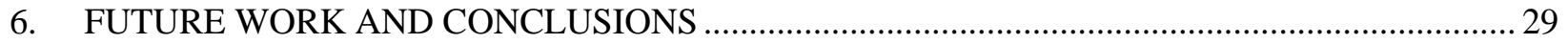

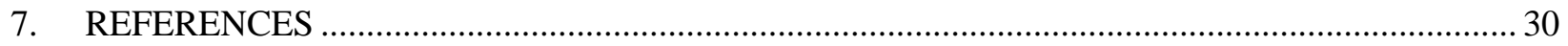




\section{LIST OF FIGURES}

Figure 1. A section of a unit cell of the MSDR core....................................................................... 8

Figure 2. A sketch of the $\mathrm{Ge}(\mathrm{Li})$ radiometric measurement system used by Houtzeel and Dyer on the MSRE. Image taken from [11].

Figure 3. Schematic of the first integration of ChemTriton with SCALE and the iterative data passing process.

Figure 4. The MSDR flowsheet developed in TRANSFORM and used to evaluate the reactor core, fission product movement, and mass accountancy.

Figure 5: A correlation heat map for the parameters and their variations (y-axis) and the responses $(\mathrm{x}$-axis) as discussed in the text.

Figure 6. Total reactor core power as a function of time for the three transient scenarios investigated as specified in Table 1 .

Figure 7: Total reactivity as a function of time for the three transient scenarios investigated as specified in Table 1 .

Figure 8: The ${ }^{135} \mathrm{Xe}$ inventory in the pump bowl of the MSDR model as a function of time for the three transient scenarios investigated as specified in Table 1 .

Figure 9. Neutron count ratios between the front cell (1) and the other cells of the HDND resulting from different sources and impurity materials.

Figure 10. SEM images of membrane material after annealing and ion exchange at various temperatures

Figure 11. Energy spectrum comparing the microcal detector to a planar HPGe detector.

Figure 12. A photo of the tested probe design showing the full size and the details of the probe tip material.

Figure 13. Images of the triple bubbler shroud showing the effects of salt climbing the shroud. ..............23

Figure 14. XRF results of measurements of $\mathrm{Sr}$ doped micro-samples of $\mathrm{LiCl}-\mathrm{KCl}$ salt samples.............. 24

Figure 15. A photo of the HKED instrument manufactured by Mirion.

Figure 16. A photo of the LIBS prototype system coupled to the aerosol generator. Image taken from $[22] .$. 


\section{ACKNOWLEDGMENT}

This report was prepared for the U.S. Department of Energy (DOE) Office of Nuclear Energy (NE) Material Protection, Accounting and Control Technologies (MPACT) campaign under the Work Package FT-20OR04010301 "Molten Salt Reactor (MSR) Safeguards - Oak Ridge National Laboratory (ORNL)". The authors would like to acknowledge and thank MPACT for funding this work. 


\begin{abstract}
Molten salt reactor (MSR) technologies, either liquid fueled and cooled or only liquid cooled, pose specific, unique challenges for safeguards of the special nuclear material during the operation, fueling, and maintenance of the reactor. MSRs are one type of Generation IV technologies being invested in and considered for U.S. domestic fabrication primarily for electricity and process heat production. These designs have generated growing commercial interest for several reasons, including high ( $\approx 40 \%)$ thermal efficiency, ease of fueling, improved use of uranium fuel, potential utilization of thorium fuel, and proposed inherent safety features. U.S. companies have several planned designs that differ in fuel, cooling, and neutron energy spectrum. Driven by commercial interest and the intent of licensing MSRs, the U.S. Nuclear Regulatory Commission (NRC) has developed a vision and strategy to accommodate non-light water reactors (LWR), which include MSRs (U.S. Nuclear Regulatory Commission 2019). In addition, the Department of Energy (DOE) through the Office of Nuclear Energy (NE) Office of Advanced Reactor Technologies (ART),
\end{abstract}

...sponsors research, development and deployment (RD\&D) activities through its Next Generation Nuclear Plant (NGNP), Advanced Reactor Concepts (ARC), and Advanced Small Modular Reactor (aSMR) programs to promote safety, technical, economical, and environmental advancements of innovative Generation IV nuclear energy technologies. ${ }^{1}$

Reactor types considering the use of salts, liquid metals, or gases for coolant fall under both ARC and aSMR. Therefore, Research Design \& Development is being pursued by DOE-NE through national laboratories, universities, and international and industrial collaborations. Additionally, the U.S. is a member of the Gen IV International Forum (GIF). The GIF is a cooperative, multinational organization to guide and carry out research and development needed for the GEN IV reactor systems (Forum 2018). GIF evaluated numerous reactor concepts and down-selected to the six most feasible advanced reactor technologies: gas-cooled fast reactor (GFR), lead-cooled fast reactor (LFR), MSR, supercritical watercooled reactor (SCWR), sodium-cooled fast reactor (SFR), and very high temperature reactor (VHTR). In support of the growing interest domestically and internationally, the Materials Protection, Accounting, and Control Technologies (MPACT) campaign, under the DOE-NE Fuel Cycle Technologies (FCT) program, engages in $R \& D$ activities by developing advanced instrumentation and analysis for safeguards and security of modern, advanced nuclear fuel cycle (non-LWR) facilities.

Because of the historic experience in the operation of the Aircraft Reactor Experiment (ARE) and the Molten Salt Reactor Experiment (MSRE) (Robertson, MSRE Design and Operations Report Part I 1965), Oak Ridge National Laboratory (ORNL) is heavily engaged in the various R\&D activities through the DOE complex related to MSRs including national technical leadership of the DOE-NE MSR campaign. This report discusses and presents the outcomes of the FY19 MPACT MSR Safeguards task. The challenges presented by MSRs for nuclear material accountancy and control (NMAC) and associated safeguards will be investigated. The objective of this research is to explore and compile the safeguards requirements and identify measurement signatures through an initial high-level MSR design and develop complementary advanced simulation and modeling capabilities. A high-level ORNL-developed MSR design called the Molten Salt Demonstration Reactor (MSDR) (Bettis, Alexander and Watts 1972) was used as the target reactor design for this research. The MSDR model incorporates technology from the MSRE and the Molten Salt Breeder Reactor (Robertson, Conceptual Design of a Single-Fluid Molten-Salt Breeder Reactor 1971). But the MSDR is a 750 MWth graphite moderated liquid fueled (low-enriched uranium) MSR compared to the MSRE's of 7.5 MWth. The focus of this report is to discuss the

\footnotetext{
${ }^{1}$ Department of Energy Advanced Reactor Technologies website - https://www.energy.gov/ne/nuclear-reactortechnologies/advanced-reactor-technologies
} 
evaluation of novel signatures, correlations, and indicators to understand the applicability of current safeguards instrumentation to MSRs using the modeling results from the MSDR. 


\section{INTRODUCTION}

\subsection{MSR SAFEGUARDS}

There is currently no concept or approach for safeguarding molten salt reactors (MSRs) by performing nuclear material accounting measurements. The objective of the study presented in this report is to determine what direct signatures from nuclear material isotopes of interest could be observed and thus potentially measured. If nuclear material signatures cannot be observed directly, indirect or correlated signatures could be used and measured for safeguards applications. This study lays the foundation for the goal of determining what existing instrumentation (currently used for safeguards applications or otherwise) could be used for nuclear material accountancy measurements in MSRs and applied without further research and development; where existing instrumentation could be modified for application to MSR safeguards; and where new instrumentation or technology development is needed.

Operating power plants have well-defined, mature instrumentation technology to monitor the reactor's power, environmental emissions, and other chemical processes. Nuclear power plants share some instrumentation with fossil fueled plants but the need for measurements to quantify materials for the purpose of safeguards is only demanded for nuclear power plants. In addition, radiometric measurements for neutron and gamma flux, effluent emission and boundary radiation are needed. MSRs are a unique type of nuclear power plant and are one of several types of Generation IV reactor designs that are being developed commercially on an international scale (Forum 2018). The fuel cycle of MSRs will be different than traditional nuclear power plants, and like fossil fuel plants, will (likely) have a continuous fuel feed compared to a stored feed. The difference between stored and continuous fuel feeding is the distinguishing factor of current reactor instrumentation (Harrer and Beckerley 1973). In addition, molten fuel salt will need to be removed to maintain the power level. This further complicates safeguards approaches for MSRs and warrants investigation.

While MSRs have operational advantages including ease of fueling and high thermal efficiency, there are significant safeguards challenges imposed by a molten salt design (whether molten salt cooled and/or liquid fueled) (Worrall, et al. 2019). The community has recognized the importance of considering safeguards needs early in the development cycle, and the stringent measures that MSRs will demand significantly outweigh the traditional (fixed) fuel cycle (International Atomic Energy Agency, International Safeguards in the Design of Nuclear Reactors 2014). This study focuses on a liquid fueled design that has inherent safeguards challenges by the inclusion of the fuel in the molten salt. Because of this, there is a continuous, time variation of fission product production and actinide transmutation in the entire system. There are no means of counting distinguishable items because the fuel is not contained in any discrete unit (like traditional reactor fuel elements that comprise fuel pin bundles) besides the core channels, pipes, and pump system. In addition, because the fission products are mobile in the salt system, it is expected that the environment where potential measurements would be made will be high radiation (dose) and high temperature areas almost immediately at startup (because of irradiated material which has had only very short cooling time - only a few tens of seconds). The purpose of this task is to determine the applicability of current safeguards instrumentation and/or where new instrumentation development is required. Naturally, a signatures evaluation study is

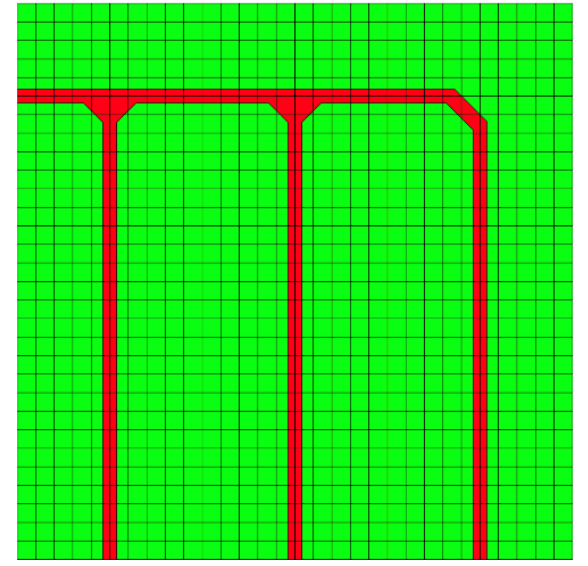

Figure 1. A section of a unit cell of the MSDR core. The green material is graphite and the red are the channels where the molten fuel/salt mixture flow. For scale, the fuel/salt channels are 0.142 (in.) in diameter (Bae, Betzler and Worrall 2019). 
needed to understand how instrumentation could be applied and used for nuclear safeguards applications in MSRs. The signature evaluation should include correlations between fission products and fissile (and/or fertile) material and other indicators of mass flow and material balance. Finding correlations between signatures that could be measured at a distance from the harsh environment yet provide information about material balance and accountancy (including diversion) is likely necessary to meet the safeguards objectives for an MSR.

\subsection{ADVANCED MODELING AND SIMULATION}

To understand the potential signatures and measurement locations for a safeguards approach to MSRs, advanced modeling and simulation research into reactor parameters has begun. The modeling efforts have been based on the MSDR (Bettis, Alexander and Watts 1972). A section of the core assembly used in the simulations is shown in Figure 1. Further details on the MSDR can be found in Bae et al. (Bae, Betzler and Worrall 2019) and Greenwood et al. (Greenwood, Betzler and Qualls 2018). The MSDR core geometry and technology adopted for illustration (off-gas system, etc.) are based closely on the Molten Salt Reactor Experiment, which operated at ORNL until 1969 (Robertson, MSRE Design and Operations Report Part I 1965) and the Molten Salt Breeder Reactor design (Robertson, Conceptual Design of a Single-Fluid Molten-Salt Breeder Reactor 1971). However, the MSDR uses a U/Pu fuel cycle as opposed to the $\mathrm{Th} / \mathrm{U}$ breeder cycle that was proposed in the Molten Salt Breeder Reactor design.

The MSDR was chosen as the target design for this signatures study primarily because it is a commercialscale MSR that shares similar features of the MSR designs under development, and thus some of the conclusions drawn from this study are expected to be applicable to other commercial reactor designs and concepts being proposed (although this comparison across designs is the subject of a separate current study). Moreover, extensive design details and plant layout information for the MSDR are available at ORNL. The latter is essential when considering instrumentation placement. Another advantage is that the MSDR design is not specific to any reactor vendor; therefore, the design information is not proprietary in nature and is publicly available. Furthermore, the selection of the MSDR design enables this work performed under the DOE-NE MPACT campaign to leverage ongoing work and analysis being performed by the DOE-NE MSR campaign based on this design.

A potential challenge exists with the available modeling tools. In particular, the isotopic time evolution and key measurement points will be design specific and therefore, the simulations have been generalized. The intent of performing these simulations is to validate any changes to the code and understand reactor operations. Generally, "operations" in this sense means reactivity, core lifetime, fission product inventory, and fissile and fertile abundances in the system. However, utilizing this information to extract signatures and/or potential measurement locations to develop a safeguards approach for MSRs is not trivial. This is especially true for measurement locations because they will be design dependent. In contrast, signature correlations could likely transfer across designs if certain key parameters are unchanged (e.g., a liquid fueled design), and, hypothetically those correlations can be studied and identified through simulations. 


\section{INDICATIVE SIGNATURES}

Previous direct radiometric measurements of fission products during the operation and shutdown periods of the MSRE (Houtzeel and Dyer 1972) can provide helpful guidance on the potential correlations that could assist in current reactor operations and safeguards signatures. In their measurement campaign, Houtzeel and Dyer (Houtzeel and Dyer 1972) recorded more than 1,000 energy spectra taken with a remotely operated, high resolution $\mathrm{Li}$ drifted $\mathrm{Ge}$ detector $(\mathrm{Ge}(\mathrm{Li}))$ on portions of the reactor fuel salt loop and off-gas piping from July to December of 1969. During this period the MSRE was critical with U/Th fuel:fission rate constituents estimated as ${ }^{233} \mathrm{U}-94 \%,{ }^{235} \mathrm{U}-2.25 \%$, and ${ }^{239} \mathrm{Pu}-3.75 \%$. An additional 400 spectra were taken as calibrations of energy and efficiency of the various geometrical configurations (i.e., the piping). One quarter of the measurements of the reactor were taken at some power level; however, most of the measurements when the reactor was at full power were either not useable or were presented only qualitatively. The objective of their work was to investigate and quantify fission product deposition behavior in certain critical areas of the MSRE. The components they focused on were the reactor off-gas system and heat exchanger - the heat exchanger contained $\sim 40 \%$ of the exposed metal surface to fuel salt. One example of a signature of interest was zirconium (Zr). Zirconium was soluble in the fuel salt and chemically follows the molten mixture. Therefore, detection of ${ }^{95} \mathrm{Zr}$ would indicate fuel salt deposition. Other isotopes of $\mathrm{Y}, \mathrm{Cs}, \mathrm{Ce}, \mathrm{Ba}$ and $\mathrm{La}$ were also expected to track with the salt.

The detector system included a laser for alignment purposes. All measurements required some form of shielding and/or collimation and significant standoff distances to reduce detector deadtime to manageable levels, which is $\leq 25 \%$ for reliable spectroscopic analysis. A sketch of the apparatus is shown in Figure 2. A general summary of Houtzeel and Dyer's work is provided here as certain notes and information are useful from a safeguards and instrumentation perspective, as applied to a commercial MSR. Specifically, the dose rates measured at certain points in the fuel salt system during operation are particularly relevant. Dose rates in the reactor cell at full power $(\sim 8 \mathrm{MWth})$ were 40,000-70,000 R/h. After shutdown and fuel drain, the dose dropped to $3,000-5,000 \mathrm{R} / \mathrm{h}$. The dose rate

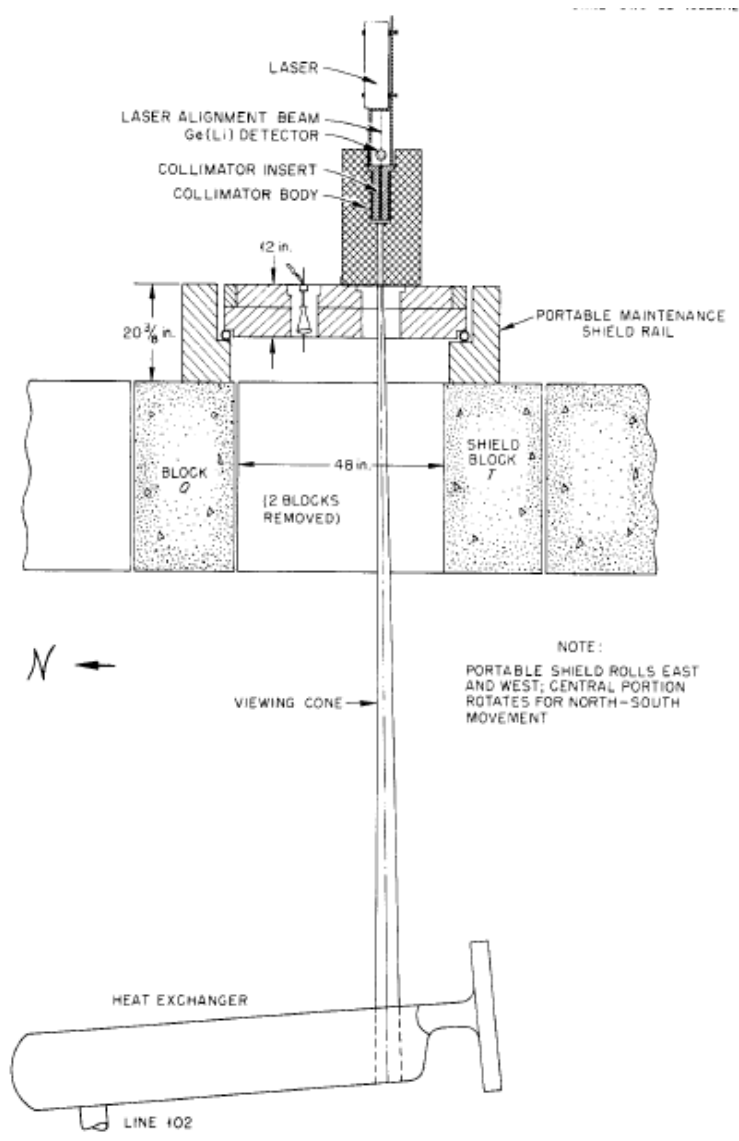

Figure 2. A sketch of the $\mathrm{Ge}(\mathrm{Li})$ radiometric measurement system used by Houtzeel and Dyer on the MSRE. Image reproduced courtesy of (Houtzeel and Dyer 1972). over a reactor off-gas line or the heat exchanger through a hole in the concrete plug shield were more than $1,000 \mathrm{R} / \mathrm{h}$ (thermal and fast neutron dose was also present). The gamma dose in the drain tank cell could be as high as $25,000 \mathrm{R} / \mathrm{h}$ immediately after shutdown and drain. Therefore, significant distance, shielding, and collimation were necessary to record gamma energy spectra. However, even with significant effort some spectra taken over the heat exchanger were not usable with the reactor at full power because of elevated count rates. 
Generally, there were areas where fission products tended to be concentrated, mainly in low-flow and baffle areas of piping. Longer lived isotopes were identified in the off-gas piping, which indicated deposition of the noble gas parents; however, ${ }^{95} \mathrm{Zr}$ was not detected in the off-gas piping. Iodine stays mobile in the fuel salt, but it can also be identified in other areas because of shorter lived metal fission products (mainly Sb and $\mathrm{Te}$ ). There were indications that fuel salt remained in the fuel pump bowl and in the line from the fuel pump to the heat exchanger by detection of ${ }^{95} \mathrm{Zr}$ gamma signatures. It is possible (although not conclusive in their study) to track activation products that could be indicative of corrosion (e.g. ${ }^{24} \mathrm{Na},{ }^{51} \mathrm{Cr},{ }^{59} \mathrm{Ni},{ }^{65} \mathrm{Ni}$, and ${ }^{60} \mathrm{Co}$ ). These isotopes were identified but cannot be positively linked to physically being in the coolant salt radiator because of the experimental conditions. Isotopes (e.g., ${ }^{24} \mathrm{Na}$, ${ }^{51} \mathrm{Cr},{ }^{54} \mathrm{Mn},{ }^{59} \mathrm{Fe},{ }^{60} \mathrm{Co},{ }^{103} \mathrm{Ru},{ }^{182} \mathrm{Ta}$, etc.) were also identified on the rouging filters from the containment ventilation, indicating activation radiation from the reactor cell and drain tank released during maintenance.

\subsection{DISCUSSION OF THE REMOTE GAMMA SYSTEM}

The investigation by Houtzeel and Dyer (Houtzeel and Dyer 1972) provides conclusive evidence for the utility of a remote gamma spectroscopy system to understand and further utilize fission (and activation) product behavior in an MSR. The time dependence of the radioactive decay chains can be leveraged as an advantage to understand plate-out and diffusion behaviors during operation, including draining and shutdown periods. This is very useful as the highly contaminated piping, and other fixtures do not have to be opened or tampered with.

Significant improvements in gamma spectroscopy hardware and software have been realized since the MSRE period of operation. This includes portable cooling options, high-purity germanium ( $\mathrm{HPGe})$ detectors that are more rugged, amplifier designs for higher throughput (transistor reset style) and digital pulse processing. Although these modifications can provide better count rates into the energy spectrum, they will not alleviate the shielding and collimation demands. It is expected that dose will roughly scale with reactor power. Thus, a significant increase in the expected gamma and neutron flux in the MSDR design would be expected. Scaling the radiation flux by reactor power would mean a two order of magnitude increase in radiation levels in the MSDR compared to the MSRE. This expectation should be further evaluated through a robust engineering study; however, the potential insight that can be provided should not be underestimated. The review of these historic measurements and expert opinion provides strong evidence that a capable system (even a network) of remote gamma monitoring may prove a valid means of safeguards and operational confirmation.

\section{DEVELOPMENT OF MODELING TOOLS}

\subsection{SCALE AND CHEMTRITON}

Proof-of-concept modeling was based on a tool developed for MSR analysis, ChemTriton, in conjunction with SCALE (Betzler, Powers and Worrall 2017, W. A. Wieselquist 2020). SCALE performed the physics transport and depletion calculations. ChemTriton is a Python script

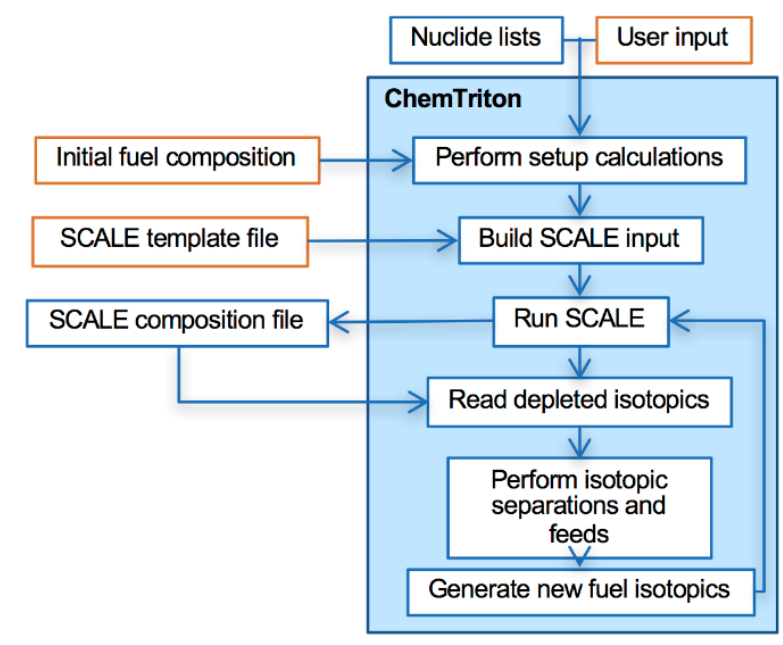

Figure 3. Schematic of the first integration of ChemTriton with SCALE and the iterative data passing process. Image reproduced courtesy of (Betzler, Powers and Worrall 2017). developed to understand the time-dependent isotopic inventory of MSRs, and the integration with SCALE is shown in Figure 3. The carrier salt of the modeled 
reactor was $\mathrm{LiF}$, enriched to $99.995 \%{ }^{7} \mathrm{Li}$ to reduce ${ }^{3} \mathrm{H}$ production via neutron capture through the reaction ${ }^{6} \mathrm{Li}+\mathrm{n} \rightarrow{ }^{3} \mathrm{H}+\alpha$ that has a cross section of $\approx 980 \mathrm{~b}$ for incident thermal $(0.025 \mathrm{eV})$ neutrons. While an endothermic reaction is possible on ${ }^{7} \mathrm{Li}$, via ${ }^{7} \mathrm{Li}+\mathrm{n} \rightarrow{ }^{3} \mathrm{H}+\alpha+\mathrm{n}^{\prime}$, it is a threshold reaction requiring incident neutron energies greater than $2.5 \mathrm{MeV}$, with a cross section greater than $0.3 \mathrm{~b}$ at $5 \mathrm{MeV}$ incident neutron energies. Since the MSDR model is a thermal spectrum reactor, the production of ${ }^{3} \mathrm{H}$ from the ${ }^{7} \mathrm{Li}$ reaction is negligible, but it is still produced as a ternary fission product. The fuel salt was $\mathrm{UF}_{4}$ dissolved in the carrier salt with $4.95 \%$ enriched ${ }^{235} \mathrm{U}$. The entire system contained $1.946 \mathrm{E} 5 \mathrm{~kg}$ of fuel salt of which $1.210 \mathrm{E} 5 \mathrm{~kg}$ were heavy metal. ChemTriton treated different chemical materials in the system as streams allowing the user to define several streams for individual tracking through iterative steps, then produce a combination of those streams to characterize a system. Modifications were made to ChemTriton to increase versatility for different types of MSRs and accept a generic SCALE/ChemTriton input file. A modeling tool that allows this type of flexibility is very useful for MSRs because systemlevel components needed for operations (e.g., noble gas sparging) can be investigated.

ChemTriton and SCALE were used to understand the impact of fission product removal from the fuel salt on reactor operations, including reactivity and changes in power with the intention of relating that to actinide inventories in the core. In addition, online refueling through the addition of fissile or fertile material after startup has also been investigated for the impact of refueling on reactivity. The implications of these changes on the MSDR have been analyzed. This analysis is a first step at relating the potential signatures for material inventory to safeguards instrumentation and the need for potential new development.

Currently, the ChemTriton code has been directly implemented into SCALE creating a faster, seamless approach to modeling continuous perturbations to the system (i.e., feeds and removals). The integration of elemental or isotope rate changes to the solution matrix allows mass flow rates to be studied based on their build up or removal. This provides the opportunity to model any potential salt type and/or treatment process.

\subsection{TRANSIENT SIMULATION FRAMEWORK OF RECONFIGURABLE MODELS (TRANSFORM)}

The Transient Simulation Framework of Reconfigurable Models (TRANSFORM) has been developed at ORNL to study the system-level dynamics of MSRs. TRANSFORM provides a way to implement system-level conditions including pipe dimensions, pump characteristics, and other details that SCALE cannot. It is based on the object oriented Modelica modeling language (M. S. Greenwood, et al. 2020). A simplified flowsheet showing the main components of the MSDR developed in TRANSFORM is given in Figure 4. The model is based on $\mathrm{LiF}_{-} \mathrm{BeF}_{2}$ (i.e., FLiBe) carrier salt enriched to $99.995 \%$ in ${ }^{7} \mathrm{Li}$ and a fuel of $4.95 \%$ enriched ${ }^{235} \mathrm{U}$ - the U/Pu fuel cycle. The current implementation for the MSDR in

TRANSFORM is based on a modified point reactor kinetics model (Greenwood and Betzler 2018). Therefore, fission products are tracked as a trace substance in the molten fuel salt mixture. The model includes the behavior coupling of fission product movement in the system with reactor kinetics and thermal hydraulics. TRANSFORM does have the ability to track the entire, comprehesive inventory of fission products and actinides. However, the level of model complexity determines the computational expense. Therefore, to alleviate this processing expense, fission product mass chains were grouped and down-selected to encompass elements that spanned the periodic table, which minimized redundant transport calculations. With this methodology, the simulations were performed on a PC in a timely fashion (minutes to hours). 


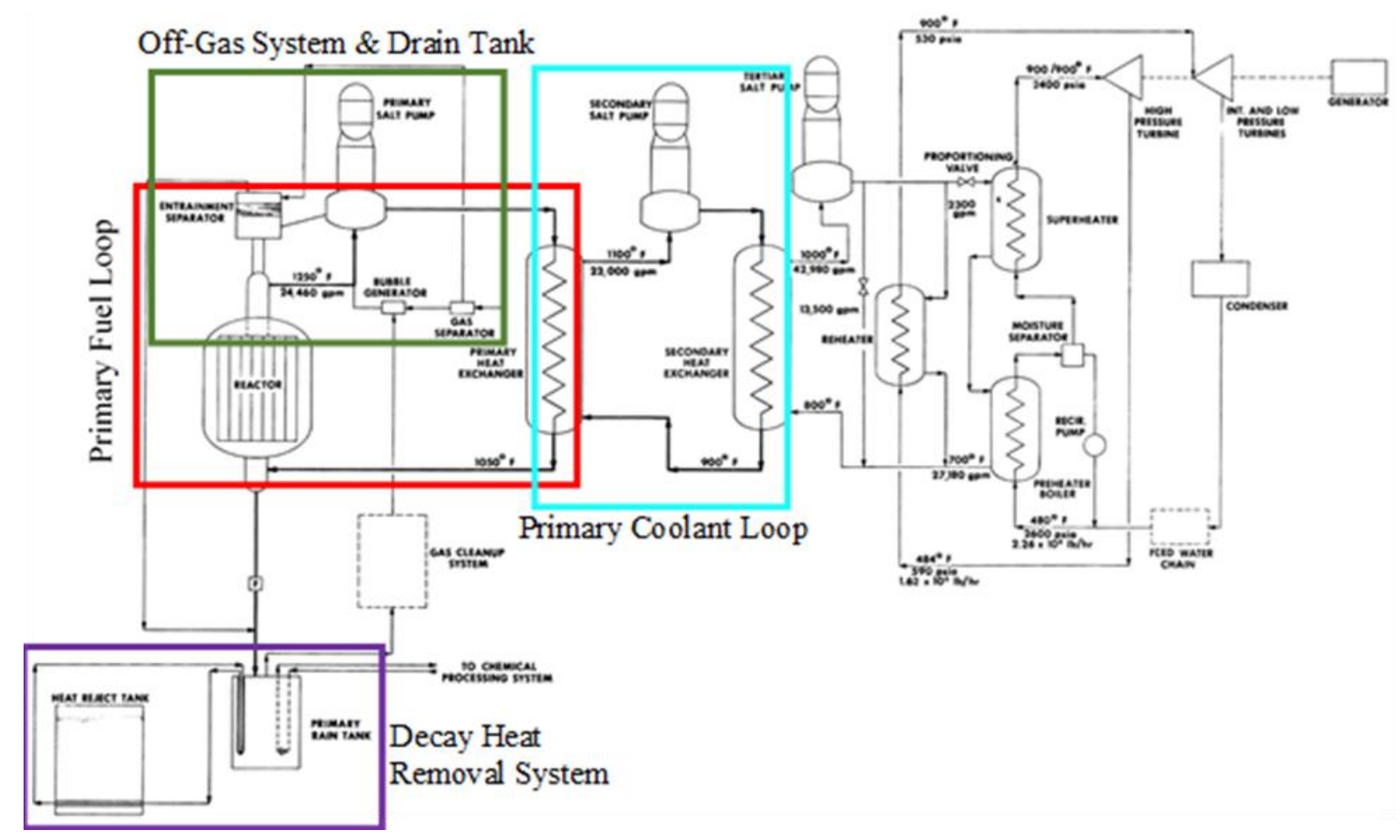

Figure 4. The MSDR flowsheet developed in TRANSFORM and used to evaluate the reactor core, fission product movement, and mass accountancy. Image reproduced courtesy of (M. S. Greenwood, et al. 2020).

\section{FY19 FINDINGS}

SCALE/TRITON and TRANFORM were used to investigate reactor parameters in the MSDR model during transient fuel salt removal and feed scenarios. As explained above, the tools varied in complexity; SCALE was focused on the core neutronics for a parametric analysis while TRANSFORM can model the reactor from a system level—including pipe dimensions, heat exchanger parameters, etc. Both models were used to simulate noble gas sparging by removing groups of isotopes based on their elemental characteristics. There were slight differences in the fuel salt composition between the modelsSCALE/TRITON was enriched ${ }^{7} \mathrm{LiF}$ and TRANSFORM used enriched ${ }^{7} \mathrm{Li}$ FLiBe salt, but both were fueled with low-enriched uranium at $4.95 \%$. The FY19 task provided a means to validate the models and can be used to investigate signatures relevant to safeguards NMAC. The findings presented below include a parametric analysis of the major and minor actinides, tritium production, etc. as reactor parameters (e.g., power, U feed), and core materials (e.g., graphite density) were perturbed within an uncertainty envelope using SCALE/TRITON. Results from the TRANSFORM simulation are shown for core reactivity and power, ${ }^{135} \mathrm{Xe}$ production in response to dynamic changes of the fuel salt feed and removal, and control of reactor power.

The modeling tools will be further developed in FY20 to provide data sets that will be analyzed to extract informative correlations of MSDR reactor operation and observables for a safeguards approach. The MSRE gamma measurement campaign will be leveraged for preliminary correlations that can be verified via the modeling effort (e.g., ${ }^{95} \mathrm{Zr}$ ) tracking with the fuel salt. The simulations will also be used to calculate the dose environment of potential measurement locations so a technology evaluation can be performed. 


\subsection{SIMULATIONS WITH SCALE/TRITON}

The complexities and (current) inexperience modeling liquid fueled MSRs allowed the development of new tools that were integrated with existing tools, including SCALE. These modifications allow reactor parameters to be understood within the MSDR. These tools can determine fuel salt composition changes during operation as well as fueling requirements and process flow rates. The modified SCALE code (as described above) was used to investigate and model perturbations within the fuel salt while monitoring the response of the system. The deviation from steady-state operations based on flow diversions are apparent with the MSDR system, including temperature, power levels, etc.

A sensitivity and uncertainty analysis using SCALE was performed to determine the expected uncertainty or confidence interval for a calculated response to quantify differences between the simulation and reality. Several different parameters and responses of interest were investigated that are directly related to fueling and reactor operations. The simulation modeled the MSDR fuel salt and moderator at a constant temperature $(898 \mathrm{~K})$ and simplified separations by grouping elements into two categories: volatile gases ( $\mathrm{Xe}, \mathrm{Kr}, \mathrm{Ar}, \mathrm{H}, \mathrm{N}, \mathrm{O}$ ) and noble metals ( $\mathrm{Se}, \mathrm{Nb}, \mathrm{Mo}, \mathrm{Tc}, \mathrm{Ru}, \mathrm{Rh}, \mathrm{Pd}, \mathrm{Ag}, \mathrm{Sb}, \mathrm{Te}$ ). Once produced these elements (and their isotopes) were immediately removed from the system. The power density was low, as expected, but the core remained critical $\left(\mathrm{k}_{\mathrm{eff}}>1\right)$ for 9.5 years. Over this lifetime, the neutron spectrum hardens with, the thermal component decreasing by a factor of about 2 . A series of simulations $(\approx 200)$ were performed for the critical lifetime of the core varying the parameters over a reasonable range of variation. The variation was determined by a literature review. A heat map showing the level of response due to the changes imposed to the parameters of the y-axis is given in Figure 5.

Although this uncertainty analysis was useful for understanding how a select range of system responses are related to the core parameters, further work needs to incorporate relevancy for a safeguards approach. So, this does provide some preliminary idea of what may be observed within operation and design uncertainties; but fuel salt diversion scenarios were not simulated. If potential diversion scenarios lie within the uncertainty response matrix, the ability to safeguard MSRs will become even more 


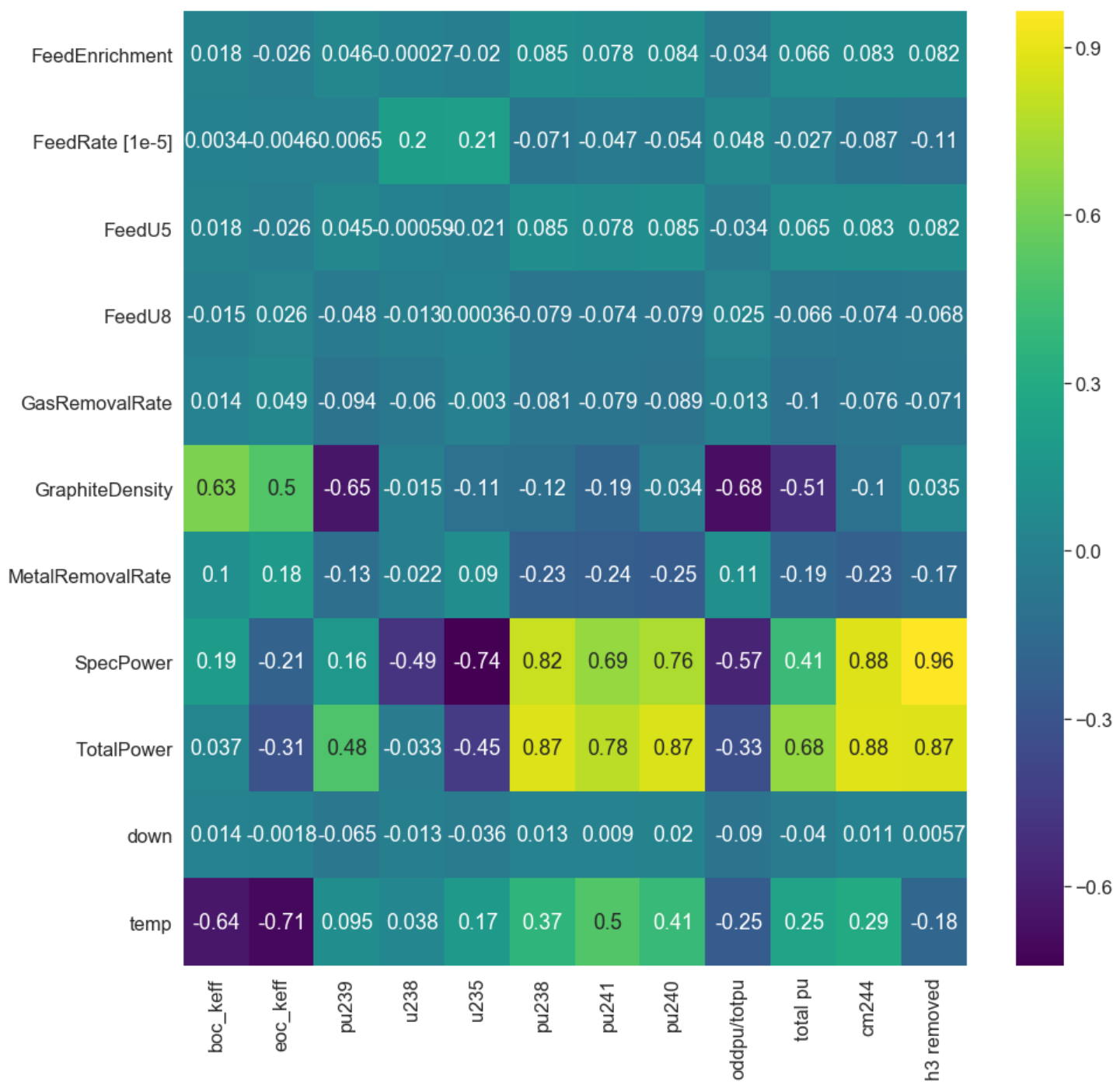

Figure 5. A correlation heat map for the parameters and their variations (y-axis) and the responses (x-axis) as discussed in the text. Each result contained in this graphic are based on a simulation of the entire critical (closed loop) run time of $\sim 9.5$ years.

complicated. But it has been demonstrated that the response of the system to various simulated changes during operation are distinguishable.

\subsection{PERTURBED INVENTORY CALCULATIONS - TRANSIENTS}

TRANSFORM was also used to investigate the response of the MSDR model to transients in the fuel salt, including addition and removal (M. S. Greenwood, et al. 2020). In these simulations the flow rate was kept constant meaning that the additive fuel salt rate was equal to the removal rate. Three different scenarios were simulated and are summarized in Table 1. There are three event drivers for these scenarios: addition of the fuel salt, removal of the fuel salt, and initiation of reactivity controls to control the power level of the reactor. The removal of the fuel salt included fission products that survive in the molten mixture without sparging in the off-gas system. 
Table 1. The description of the three scenarios investigated with TRANSFORM using the model of the MSDR.

\begin{tabular}{cl} 
Scenario & Description \\
\hline \multirow{2}{*}{ A } & $\begin{array}{l}\text { Step change in salt removal/addition } \\
\text { No reactivity control }\end{array}$ \\
\hline \multirow{2}{*}{ B } & $\begin{array}{l}\text { Periodic step changes in salt removal/addition } \\
\text { No reactivity control }\end{array}$ \\
\hline \multirow{2}{*}{ C } & $\begin{array}{l}\text { Periodic step changes in salt removal/addition } \\
\text { Reactivity control to hold power constant }\end{array}$
\end{tabular}

The simulations with these transients were examined over a 12 hour period. Figure 6, Figure 7, and Figure 8 are the results of this simulation, including the total core power (MW), total reactivity $(-)$, and ${ }^{135} \mathrm{Xe}$ atom concentration in the pump bowl (atoms]), respectively. These data can be interpreted qualitatively and account for operating conditions of the reactor. The data do exploit the coupling and sensitivity of the fuel salt composition to observables in process monitoring (core power) and radiometric signatures $\left({ }^{135} \mathrm{Xe}\right.$ activity and subsequent signature emissions). Therefore, it is encouraging to exploit and investigate simulations such as these to determine how these data can be leveraged for safeguard applications. For example, the ${ }^{135} \mathrm{Xe}$ concentration time dependency for scenario $\mathrm{C}$ is more sensitive to the fuel salt removal/addition than the reactivity; note, in this transient situation the operation has maintained stable power as indicated in the blue dash dot curve in Figure 6. In comparison, with periodic transient fuel salt addition and removal but without reactivity control (scenario B), all three observables (power, reactivity and ${ }^{135} \mathrm{Xe}$ atoms) demonstrate a time variation likely proportional to the fuel salt transient condition. In this scenario it is interesting to point out that the ${ }^{135} \mathrm{Xe}$ does not continuously build up (as in scenario A) since it is being removed

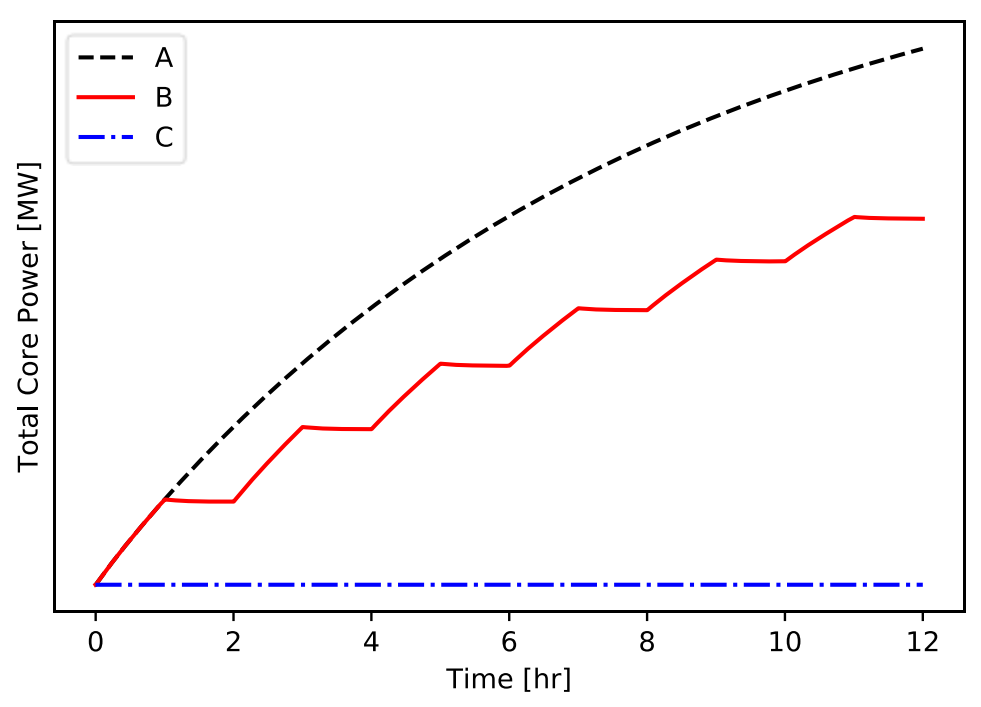

Figure 6. Total reactor core power as a function of time for the three transient scenarios investigated as specified in Table 1.

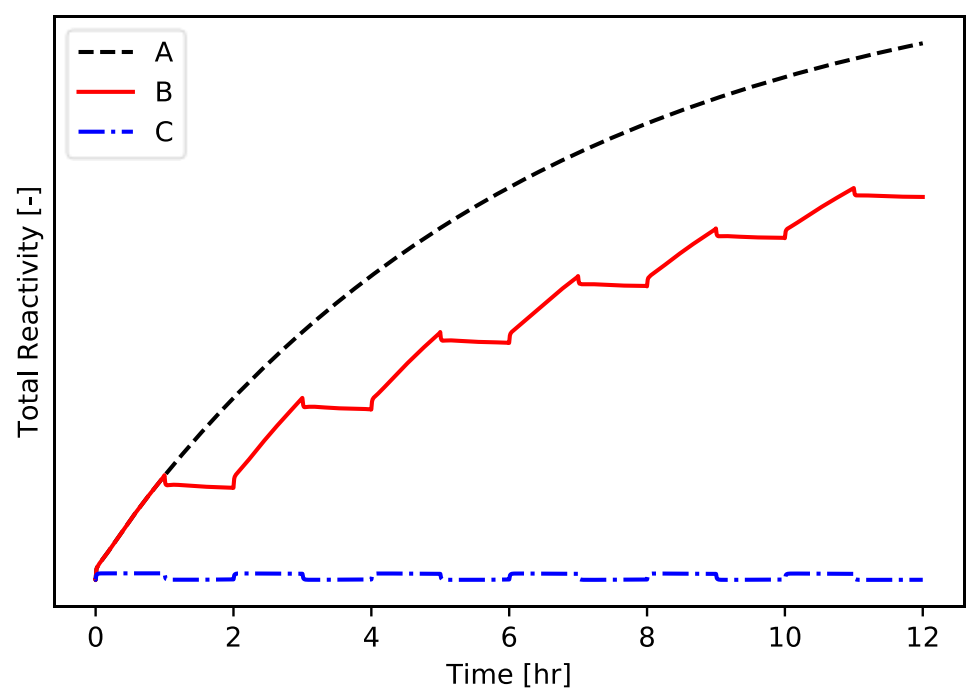

Figure 7: Total reactivity as a function of time for the three transient scenarios investigated as specified in Table 1. 
from the system through the fuel salt removal process. These scenarios were simulated to understand and observe the tight coupling between the fuel salt and potential observables, but it is unlikely that these conditions would be "normal" operations for a commercial MSR. However, the coupling is an important feature that implies the declared operation should stay within well-defined limits. Joint use instrumentation designed to control the reactor that provides information into a predictive model of reactor performance is a potential means to obtain safeguard verification of the declared operational intent.

\subsection{CURRENT (SAFEGUARDS) INSTRUMENTATION UTILITY}

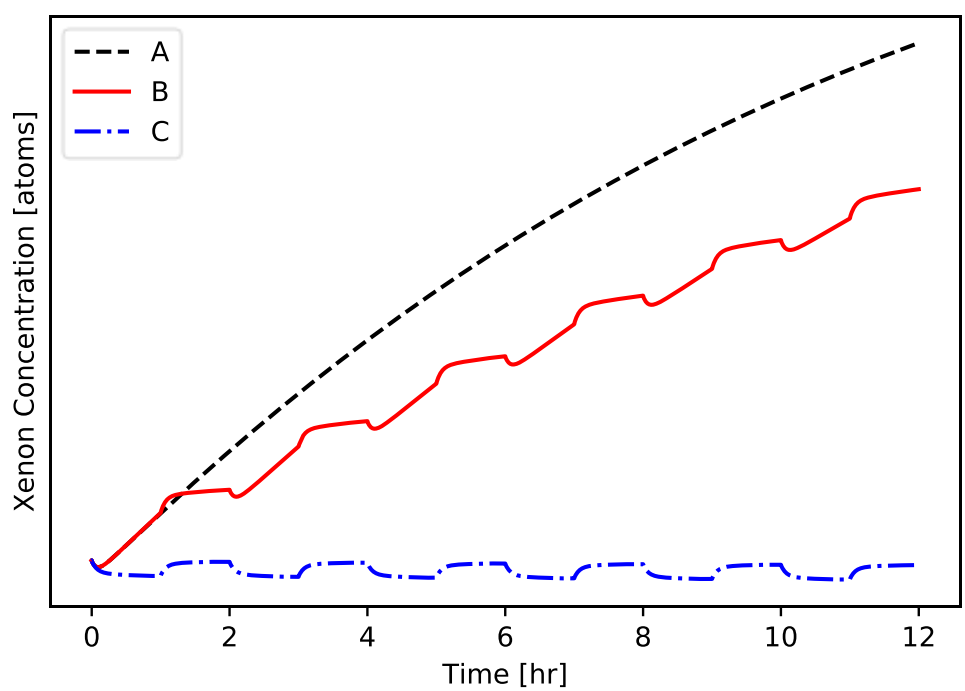

Figure 8: The ${ }^{135} \mathrm{Xe}$ inventory in the pump bowl of the MSDR model as a function of time for the three transient scenarios investigated as specified in Table 1.

The technical differences between traditional fixed fuel reactor technology (LWRs) and any variant of an MSR is going to influence how applicable instrumentation is used and (likely) demand development of new hardware for safeguards-relevant measurements. A goal of international safeguards is to detect the diversion of a significant quantity of nuclear material in a timely manner. A significant quantity of nuclear material is defined by the International Atomic Energy Agency (IAEA) (International Atomic Energy Agency, International Atomic Energy Agency Safeguards Glossary 2001) (e.g., 8 kg of Pu containing less than $80 \%{ }^{238} \mathrm{Pu}$ ). The common approach to safeguards is to combine various technical safeguards methods to achieve a target likelihood of timely detection of diversion of material, as defined in the State Level Approach. The technical safeguards measures are grouped into the following categories, among others:

- Nuclear Material Accountancy (NMA): Takes place inside of a material balance area and utilizes measurements and the analysis of data to accurately account for the material at a facility.

- Surveillance, Containment and Monitoring Measures: These methods support NMA by the ability to identify access, change, or other perturbations to any nuclear material or installed safeguards equipment. Seals, cameras, and other sensors provide a means to store data and maintain a "continuity of knowledge."

- Process Monitoring (PM): Is a method to use the instrumentation in place for operation of the facility to supplement and complement NMA (Burr, et al. 2012). Examples of typical

data/instrumentation that may be available in a reprocessing plant are mass and density, flow meters, and temperature measurements in the various stages of processing.

Nondestructive assay (NDA) methods are used extensively to measure and, in most cases, leverage the emission signatures to quantify nuclear material. NDA techniques include gamma-ray spectroscopy, neutron counting, and calorimetry. The NDA can be passive and/or active interrogation methods. There are numerous mature NDA systems implemented in various safeguards applications; ranging from fresh fuel verification to spent fuel measurements. But, because domestic safeguards requirements are yet to be completely defined for MSRs and designer concepts have not been fully developed, it is difficult to provide a detailed evaluation of NDA technology to safeguards for MSRs. However, because of the 
conditions within any proposed MSR design — specifically radiation dose — one approach could be to define a material balance area that encompasses a vast portion of the MSR or the entire facility. The safeguards approach could heavily rely on seals, cameras, remote radiation detectors and other instrumentation that would transmit data securely to a database. The data could be evaluated in real-time or processed in sequence with operational events (maintenance, fueling, draining, etc.) to identify misuse of the facility and/or detect indications of material diversion. This approach would require robust methods of gathering and transmitting data securely similar to methods used by the IAEA (International Atomic Energy Agency, IAEA Bulletin: Preventing the Spread of Nuclear Weapons 2016).

In addition to traditional NDA systems, there has been significant technological development under MPACT for pyroprocessing systems and through the DOE Advanced Reactor Technologies research and development (R\&D). Given these restrictions, a general evaluation of the R\&D technology can be discussed. The outcomes of a review panel performed in May 2019 (L. Worrall, S. Croft, L. Qualls and A. Worrall, unpublished) provides some guidance for the evaluation. There are several considerations, assumptions, and unknown parameters regarding any potential measurement at a functional MSR facility:

- Variability of MSR design and fuel cycle: MSRs can support various designs with different fuel cycles. This implies that an NMA safeguards program will need to also change to accommodate these variations requiring a site by site implementation.

- Coupled fuel cycle operations and reactor: In a liquid-fueled MSR, there may be online and continuous processing, fuel feed, and fuel removal. This strongly ties the fuel cycle to reactor operations.

- Changing, flowing material: The isotopics and chemistry of the fuel salt will be continuously changing throughout the fuel cycle. This will demand an evaluation of measurement time dynamics and frequency.

- Measurement environment and accessibility: Potentially all areas of an MSR facility will be highly radioactive. In addition, high temperatures are expected, and measurements of direct fuel salt are difficult because of the corrosive nature of the salts and the coupling of corrosion to the elevated temperatures. Remote monitoring and data collection, and detector state-of-health, and robustness will be necessary.

- Definition of functional and regulatory requirements: Functional requirements will be defined for the technologies deployed for NMA in MSRs. In addition, requirements for a domestic safeguards program for MSRs are not defined. Detection thresholds, measurement accuracy and precision, and timeliness of detection technologies for NMA will be determined by these requirements. 


\subsubsection{Detector Technology}

The High-Dose Neutron Detector (HDND) being developed at the Los Alamos National Laboratory is based on a form of ${ }^{10} \mathrm{~B}$ proportional counter technology. Thermalization of fast neutrons is accomplished with high-density polyethylene (HDPE). Neutron counting is optimized by the geometry of the HDPE and the six proportional counter cells. The current ("standard") size acquires list mode data from each of the cells that have fast amplifiers to reduce dead time and allow for mixed field analysis (neutron and gamma). Multiple pods can be used for coincidence counting applications. This technology was tested with MOX fuel pins and demonstrated maximum gamma rates up to $\sim 35,000$ and $\sim 350 \mathrm{cps}$ neutron (for nine fuel pins) of an individual detector output (1/6 of the total detector module). The approximate gamma dose during measurements ranged from 15 to $100 \mathrm{R} / \mathrm{h}$. Data analysis techniques comparing the cell neutron response can be used for multiplicity counting and extracting the neutron energy spectrum,

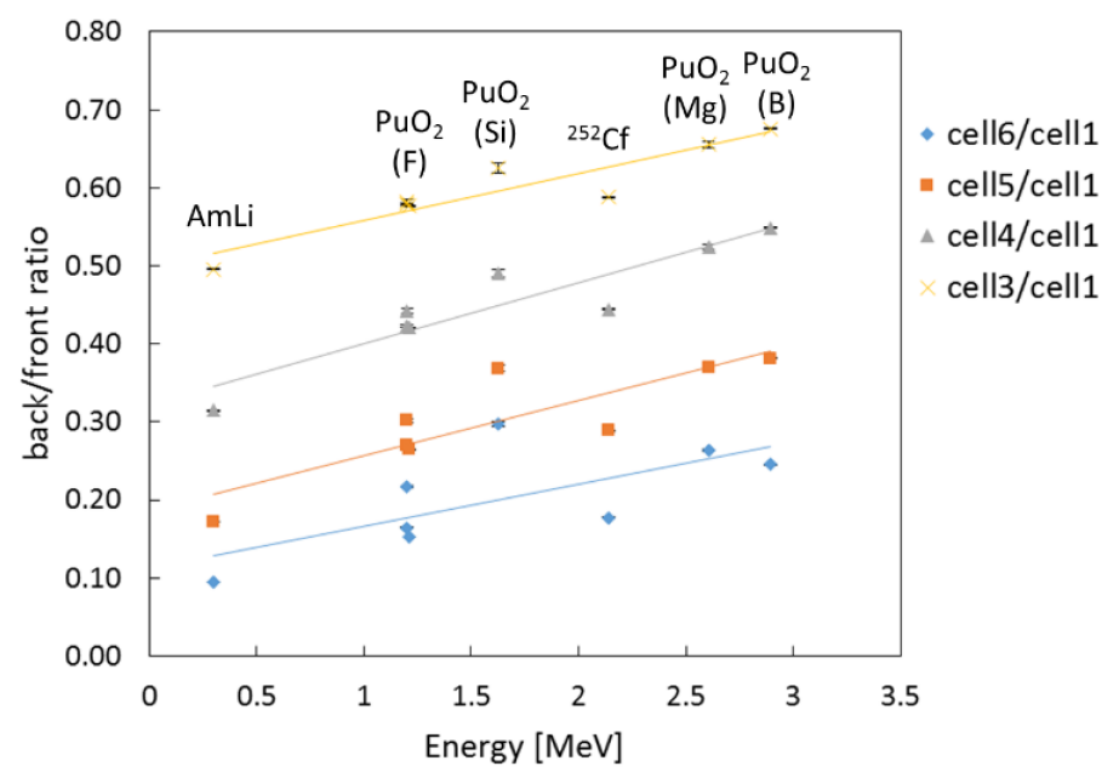

Figure 9. Neutron count ratios between the front cell (1) and the other cells of the HDND resulting from different sources and impurity materials.Image reproduced courtesy of Henzlova, D. and Menlove, H. O., MPACT Working Group Meeting, April 2019.

see Figure 9. Dose rates in a commercial MSR would be significant. If a linear relationship is assumed between operating power and dose (as an approximation), using the provided values from the MSRE as a starting point would extrapolate to values several orders of magnitude higher than the as tested conditions of the HDND. Therefore, for application in extremely high dose areas, the electronics would have to either be shielded or placed remotely. In addition, pulse rates and dead time would need to be evaluated to understand the detector response in this high-rate environment. 
The online actinide sensor being developed by the Argonne National Laboratory (ANL) is to monitor actinide concentrations during electrorefining. An electrode geometry is inserted in a molten salt ( $\mathrm{LiCl}-$ $\left.\mathrm{KCl}-\mathrm{UCl}_{3}\right)$ as the potential between the electrodes varies logarithmically with actinide concentration. An analysis of membrane materials and temperature behavior has been performed, including microanalysis after temperature cycling and annealing, see Figure 10. Microcracks develop under prolonged temperature

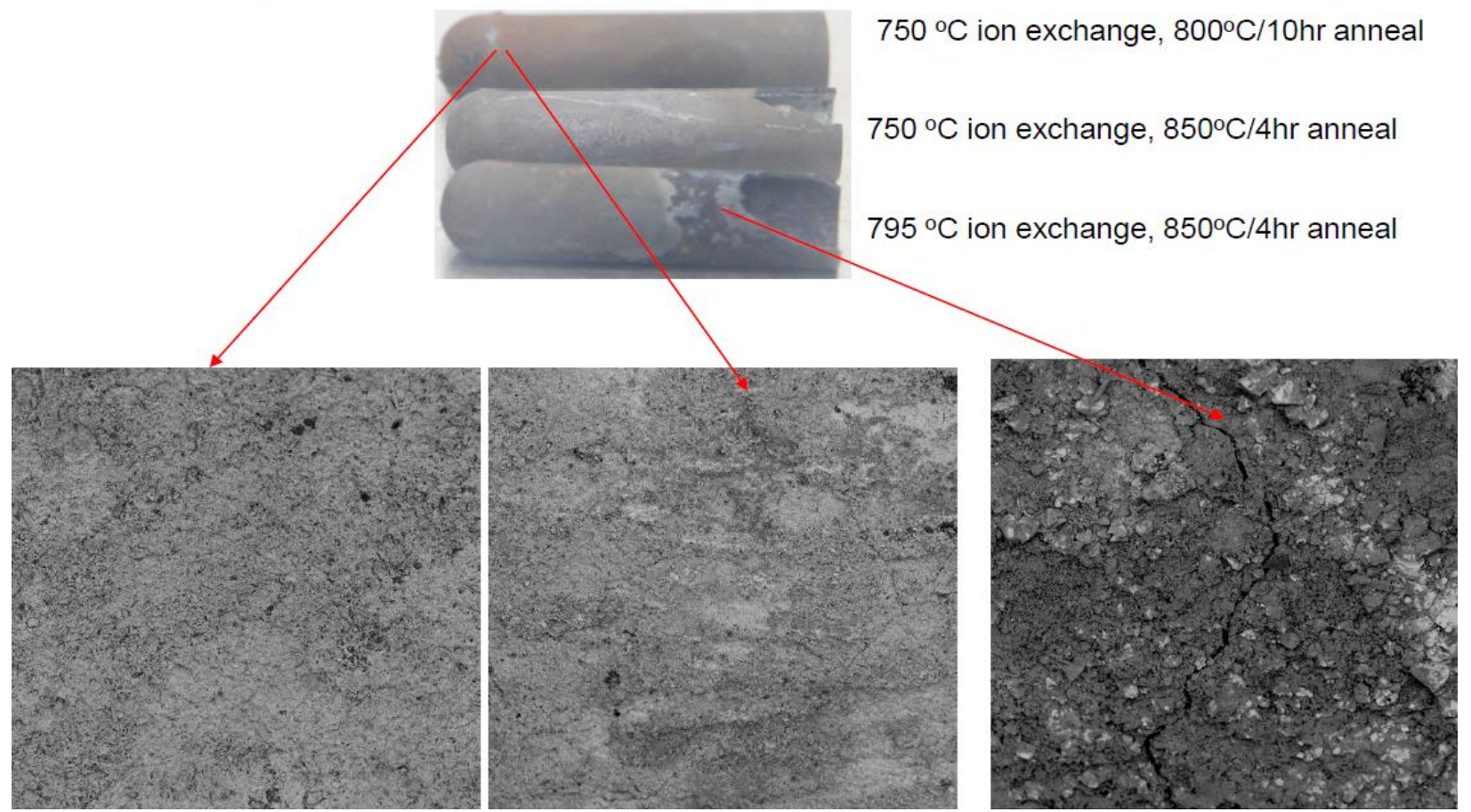

Figure 10. SEM images of membrane material after annealing and ion exchange at various temperatures.Image reproduced courtesy of Cao, G. et al., MPACT Working Group Meeting, April 2019.

and salt submersion. Further development of the sensors is required. However, proof-of-concept selectivity to salt addition and sensitivity to concentration changes has been observed.

The In Situ Actinide Monitor is being developed at the Idaho National Laboratory. The concept is based on temperature measurements of U-Pu alloys, and by means of phase transitions the composition of a mixture can be determined. Measurements were made with Type $\mathrm{K}$ thermocouples and the equipment and furnace was calibrated with pure $\mathrm{Ag}$ and $\mathrm{Al}$ metals (at least $99.9 \%$ purity). Experiments were performed with three different samples that varied in mass and weight percent $\mathrm{Pu}$. Using the internal offsets found through the use of the pure metals, the samples were characterized as shown in Table 2. The application of this technique to molten salts (and/or fuel salts) would have to be experimentally determined. Also, the longevity of the thermocouples to the corrosive salt would need to be understood. However, the simplicity of the measurement and being able to make standoff measurements and move the data acquisition hardware away from the radiation area should be trivial.

The Ohio State University is developing a wide bandgap alpha detector for application to pyroprocessing. Fabrication of a detector and characterization to measure actinides in molten salts up to $500{ }^{\circ} \mathrm{C}$ is being pursued. The detector material is a wide bandgap semiconductor material $(4 \mathrm{H}-\mathrm{SiC})$. The detector fabrication and packaging are customized for the application. Demonstrated results by direct electrodeposition of $\mathrm{U}$ on the diode for analysis of ${ }^{234} \mathrm{U}$ to ${ }^{238} \mathrm{U}$ concentration in a $2 \% \mathrm{LiCl}-\mathrm{KCl}-\mathrm{UCl}_{3}$ salt have been performed. The preliminary results are shown below in Table 3 . 
Table 2. Results of the measured Pu weight percent of three samples using the In Situ Actinide Monitor. Data reproduced courtesy of taken from Westphal, B., et al., MPACT Working Group Meeting, April 2019.

\begin{tabular}{cllll}
\hline U-Pu Alloy & Mass [g] & $\begin{array}{l}\text { Measured Pu } \\
{[\text { wt. \%] }}\end{array}$ & $\begin{array}{l}\text { Calculated Pu } \\
\text { [wt. \%] }\end{array}$ & \% Difference \\
\hline 1 & 97 & 32.12 & 33.75 & 5.07 \\
\hline 2 & 81 & 37.86 & 38.80 & 2.49 \\
\hline 3 & 66 & 47.50 & 52.12 & 9.73 \\
\hline
\end{tabular}

Table 3. Measurement results of the $4 \mathrm{H}-\mathrm{SiC}$ detector compared to a traditional $\mathrm{Si}$ detector. Data reproduced courtesy of Cao, L. Raymond, MPACT Working Group Meeting, April 2019.

\begin{tabular}{ccc}
\hline Sample & Activity Ratio ${ }^{234} \mathrm{U}^{238} \mathrm{U}$ & $\begin{array}{c}\text { Isotopic Concentration of }{ }^{234} \mathrm{U} \\
\text { (wt. \%) }\end{array}$ \\
\hline Natural U & 0.99 & $5.3 \times 10^{-3}$ \\
\hline SiC Detector & $0.089 \pm 0.007$ & $4.7 \pm 0.4 \times 10^{-4}$ \\
\hline Si detector & $0.097 \pm 0.007$ & $5.2 \pm 0.4 \times 10^{-4}$ \\
\hline DU sample & $0.105 \pm 0.007$ & $5.6 \pm 0.4 \times 10^{-4}$
\end{tabular}

Los Alamos National Laboratory has developed microcalorimeters and demonstrated larger arrays with signal processing at advanced technology readiness. The energy resolution is 10x better than high-purity germanium (HPGe) and can resolve numerous isotopic signatures in the energy region of $<200 \mathrm{keV}$. Field

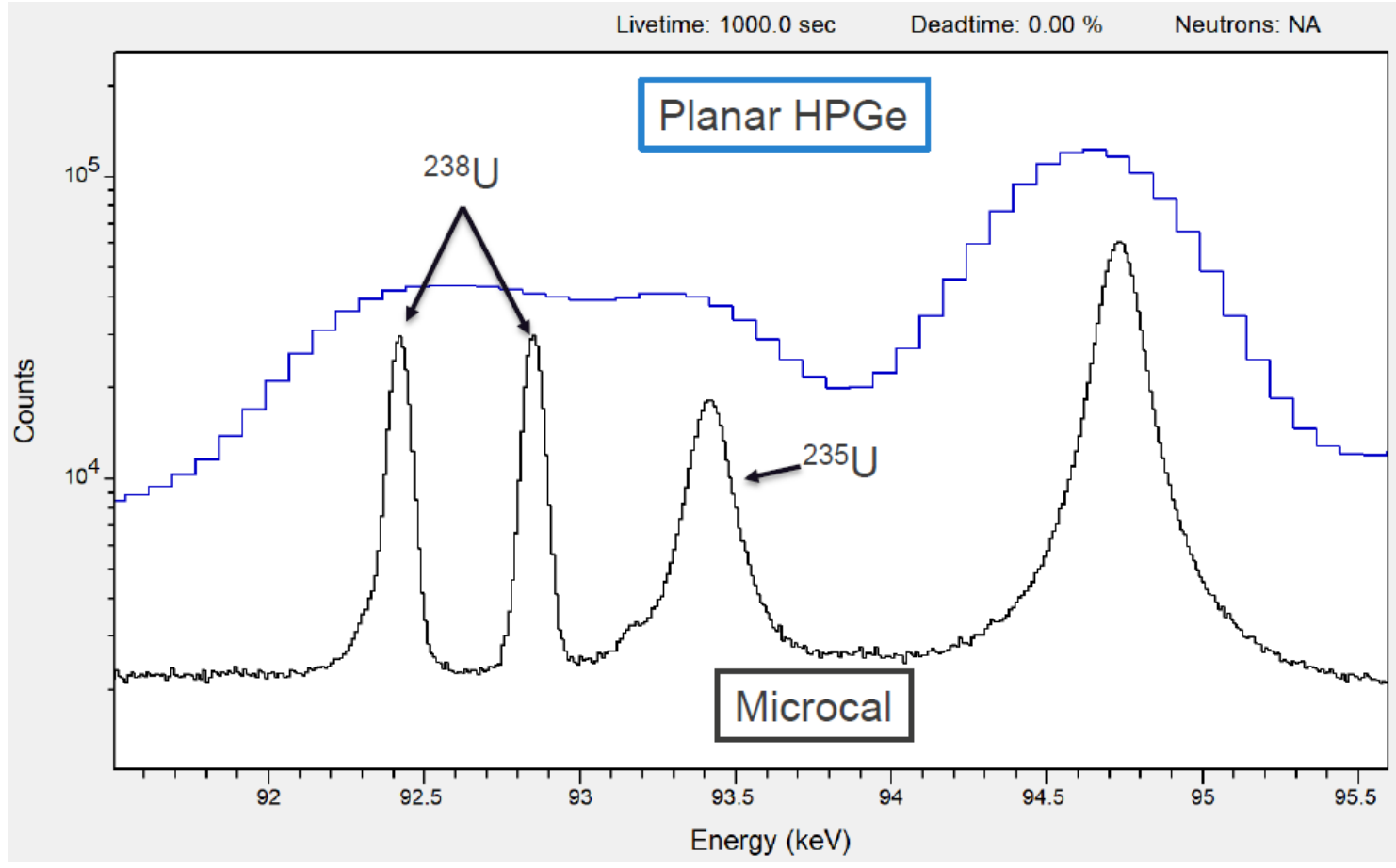

Figure 11. Energy spectrum comparing the microcal detector to a planar HPGe detector. Figure reproduced courtesy of Croce, M., MPACT Working Group Meeting, April 2019. 
testing and measurements of different samples have been demonstrated. It is unclear what the incident particle rate restrictions/limitations are which are useful for direct MSR measurements (either salt, coolant, or off-gas system). And the sensitivity of the electronics to neutron damage and having a significant standoff with required cooling technology would be difficult to implement. However, the utility of the system should be evaluated further for potential grab sample evaluation in a facility. An energy spectrum of a U sample is shown in Figure 11.

The triple bubbler is process monitoring technology being developed at ANL for determining density and depth of molten salts. The measurement is made with three probes of various length inserted directly into the molten salt. The density is mathematically derived from pressure differentials resulting in measurable quantities across the probes. Difficulties were experienced with random readings of probes in salt mixture with temperatures of $475{ }^{\circ} \mathrm{C}$ and then $525^{\circ} \mathrm{C}$. Therefore, a new design is being produced to address these issues. Whether or not this technology can be used in flowing molten salts is yet to be determined. Further investigation needs to be performed. An image showing the probe shroud after exposure in molten salt for 5 days is given in Figure 13.

Voltammetry techniques are being developed at ANL for in situ molten salt measurements of salt composition. Relatively simple hardware using probes directly submerged in the molten salt to measure the current as a function of a change in voltage. Tungsten and iridium probes are being investigated for measurements of $\mathrm{LiCl}+\mathrm{Li}_{2} \mathrm{O}$ salts with changing weight percent of $\mathrm{Li}_{2} \mathrm{O}$, see Figure 12. The results were not as expected. Material plated out on the $\mathrm{W}$ probe and it eventually broke and failed (corrosion). A new prototype is under development. Further investigations would need to be performed to evaluate the corrosion resistance and sensitivity of this technique. 

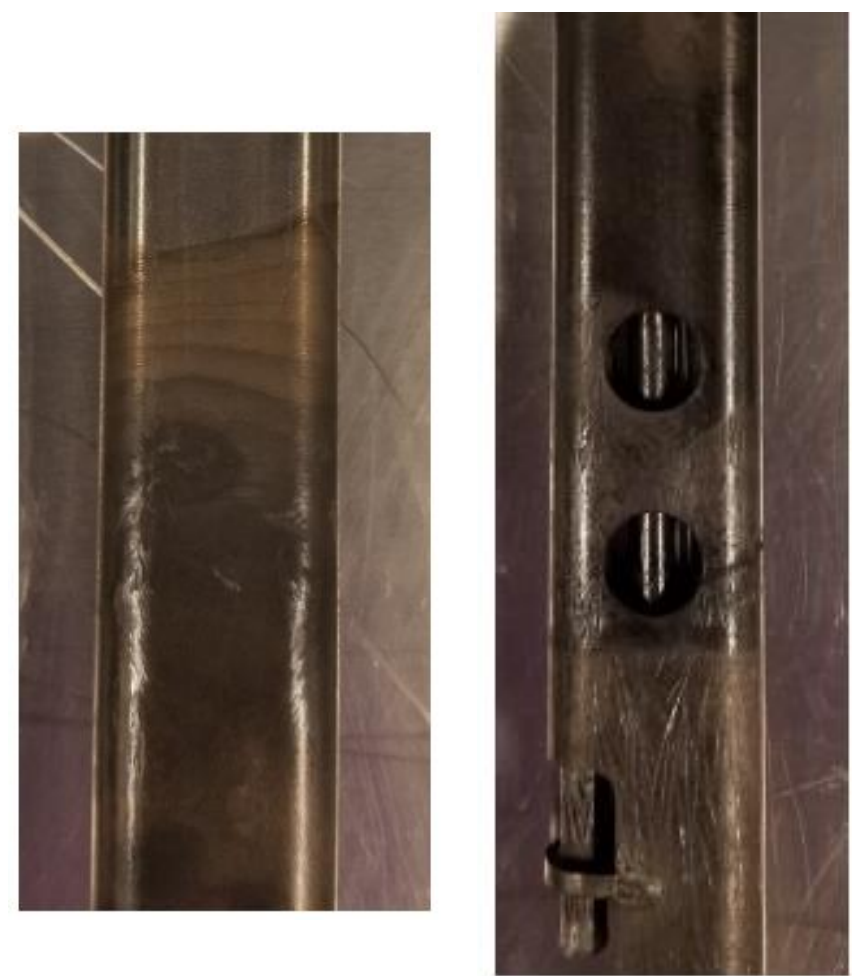

Figure 13. Images of the triple bubbler shroud showing the effects of salt climbing the shroud.Figure reproduced courtesy of Williams, A., Galbreth, G. and Sanders, J., MPACT Working Group Meeting, April 2019.

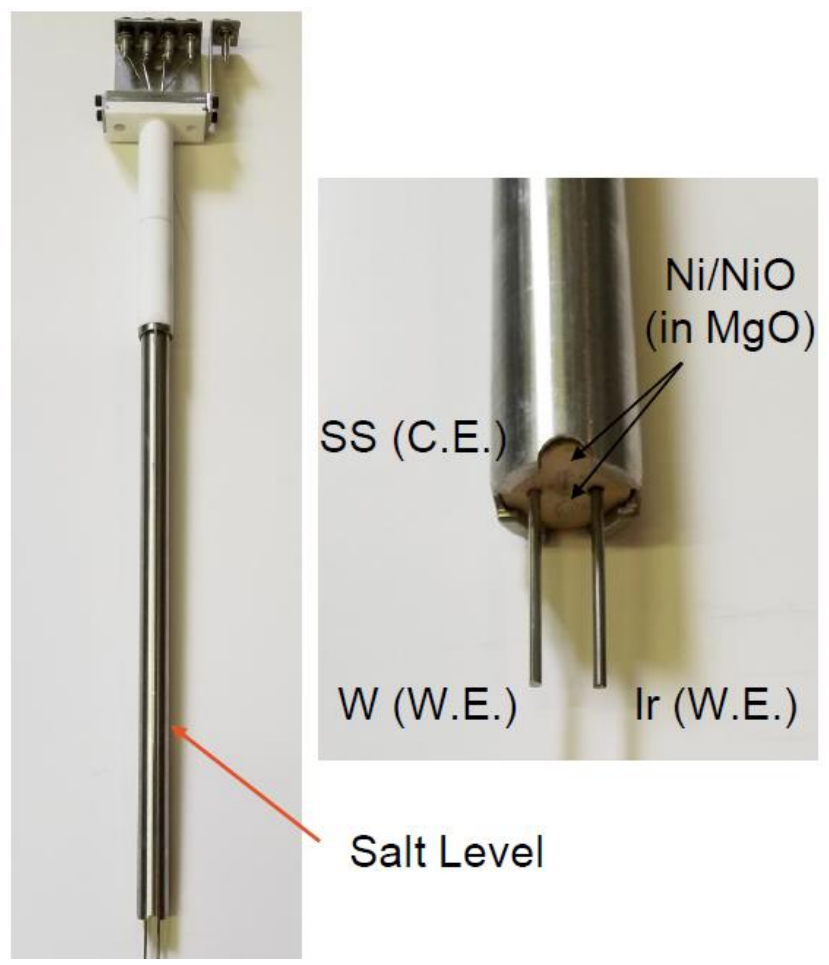

Figure 12. A photo of the tested probe design showing the full size and the details of the probe tip material.Figure reproduced courtesy of Williams, $A$. and Cao, G., MPACT Working Group Meeting, April 2019. 
Automated high-throughput micro-sampling and analysis for process monitoring has been investigated by ANL for implementation in electrochemical reprocessing scenarios. The application to an MSR needs to be explored further. It is likely that salt samples will have to be evaluated periodically (on a time scale to be determined) during operation of the reactor. These samples can be destructively or nondestructively analyzed for radioisotope measurements and for chemical evaluation. The proposed sampling method has potential benefits such as high sample throughput and production but has not been thoroughly evaluated with corrosive, radioactive salts. Results have shown sensitivity with x-ray fluorescence measurements of Sr doped salts, see Figure 14. Additionally, how the microdroplets would respond to the environmental setting in a reactor (including vibration from pumps and motors etc.) would have to be examined. Also, more research would have to be performed to understand how and what analytical equipment would be needed and how it would be integrated into the system.
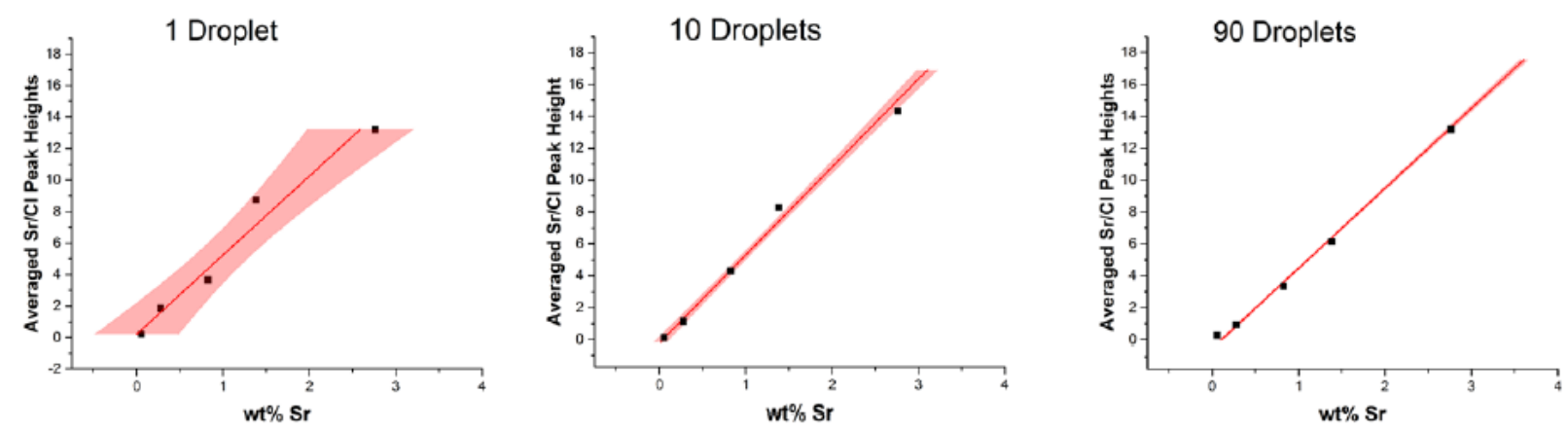

Figure 14. X-ray fluorescence results of measurements of $\mathrm{Sr}$ doped micro-samples of LiCl-KCl salt samples. Figure reproduced courtesy of Launiere, C. and Pereira, C., MPACT Working Group Meeting, March 2017.

The Hybrid K-Edge Densitometer (HKED) is optimized for actinide concentration measurement in aqueous samples generated at spent fuel reprocessing plants Figure 15. The HKED can determine U and $\mathrm{Pu}\left(\mathrm{g} \cdot \mathrm{L}^{-1}\right)$ at less than $1 \%$ accuracy far more quickly and at a lower cost than chemical methods. For accountancy tank measurements it is an extremely important device because of its accuracy and throughput. It potentially could be adapted to measurements of MSR salt samples, but a strategy would need to be devised to derive aqueous samples from the molten salt. HKED would likely be a complementary analytical tool to DA methods in much the same way as it is used at reprocessing facilities. How to take such samples is the subject of ongoing R\&D. Samples will need to be representative, and the issues of material migration and salt freezing within the sample lines must be overcome. However, caution is due because pulling samples can also be viewed as a breach of an otherwise (nominally) sealed system.

Tests on representative salt solutions, which differ in elemental composition to accountancy tank solutions, are needed. Estimations based on ongoing R\&D efforts of concentrations over the operation life of the reactor are needed. Obtaining various samples from the reactor facility (salt loop) could be used to confirm material $(\mathrm{Pu})$ is not being diverted - although converting from grams per liter or grams per gram to mass inventory would likely not be viable given the difficultly in estimating the volume of the system. Another potential role for the HKED technique in MSRs is for continuous online monitoring. This would require an $R \& D$ effort to design integration of the instrument with a sampling pipe that is at plant operation temperature to keep the sample molten. The advantage of HKED measurements compared to 
other approaches is that the instrument itself is entirely outside the salt stream, and thus not subjected to the extreme radiation, chemical, and thermal environments as in-core instruments.

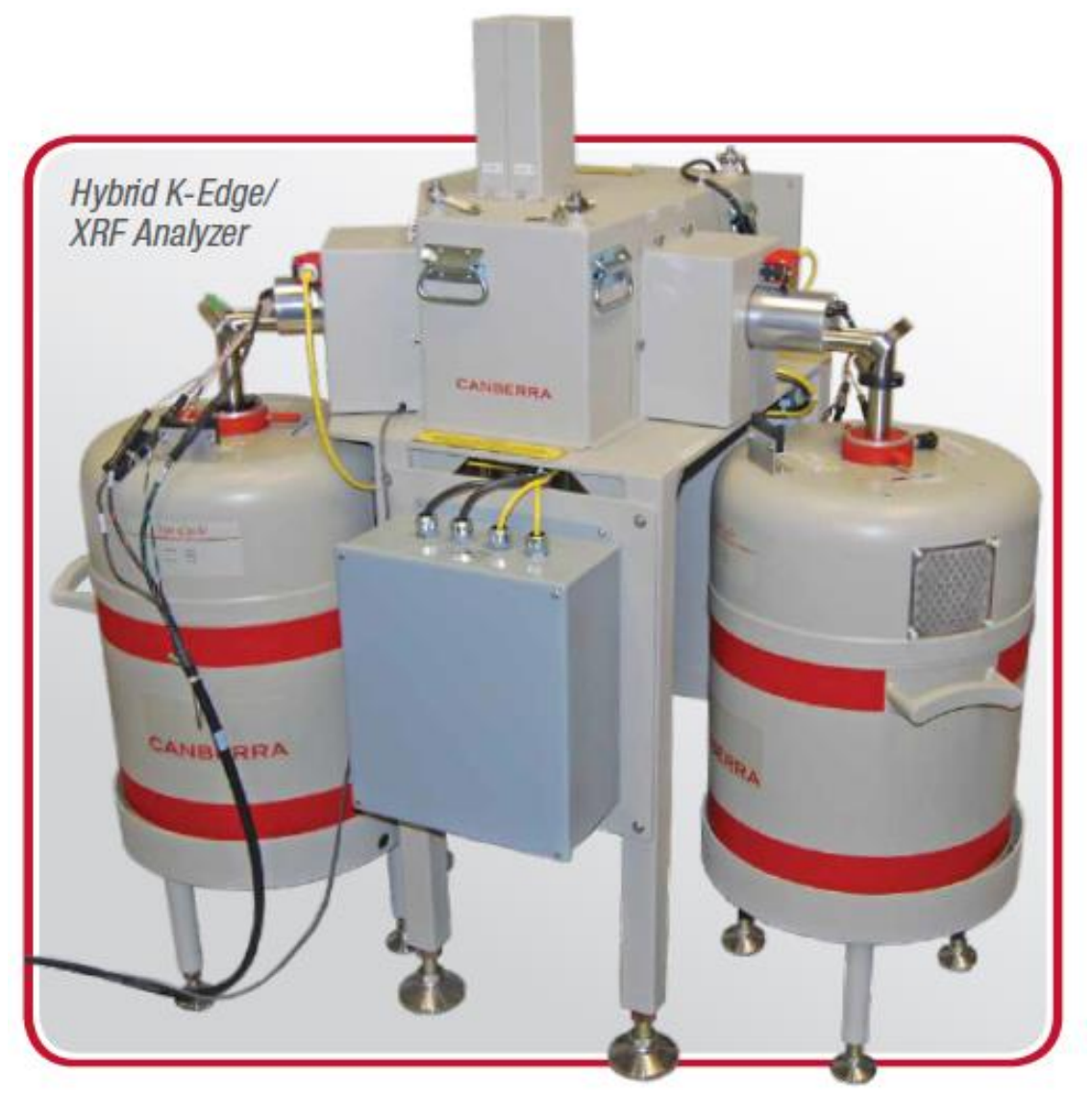

Figure 15. A photo of the HKED instrument manufactured by Mirion.Figure reproduced courtesy of (Mirion (Canberra) n.d.). This unit is similar to the instrument at ORNL for algorithm development and system R\&D.

Technology development for the off-gas monitoring system of an MSR is necessary. A laser induced breakdown spectroscopy (LIBS) system is being developed at ORNL to monitor the aerosol effluents in the off-gas stream. LIBS is based on excitation of atoms that have been generated by the incident laser energy on a sample. The detection of the emitted characteristic frequencies of light allow detection of the elemental constituents of a sample and isotopic information. Typical detection is in the parts per million range. A surrogate aerosol generator (a collision nebulizer) and prototype LIBS system including a sampling chamber has been demonstrated with room temperature aqueous samples, Figure 16. Initial testing of the system has been performed with pure $\mathrm{Fe}$ and $\mathrm{La}$ in an aqueous solution and $\mathrm{CrCl}_{3}-\mathrm{KCl}-$ $\mathrm{MgCl}_{2}$ aerosols at concentrations from 0 to $1,000 \mathrm{ppm}$. The limit of detection for $\mathrm{Cr}$ in solution was $55 \mathrm{ppm}$ based on the $427.6 \mathrm{~nm}$ emission. Demonstration of the LIBS system with a dynamic range of elements and isotopes will be pursued as well as integration with the planned molten salt loop and hydroxide scrubber. Of course, testing a system with the radiation and temperature environment of an MSR will be necessary to fully evaluate the performance and design the components (including electronics) to have long-term utility.

\subsubsection{Joint Use or Existing Instrumentation}

Core monitoring instrumentation has been investigated thoroughly for thermal power reactors including pressurized water reactors and boiling water reactors. Most detectors for neutron measurements in nuclear 
reactor environments are gas-based. A brief overview of the technology is given here; for a more thorough discussion see Holcomb et al. (Holcomb, Kisner and Cetiner 2018).

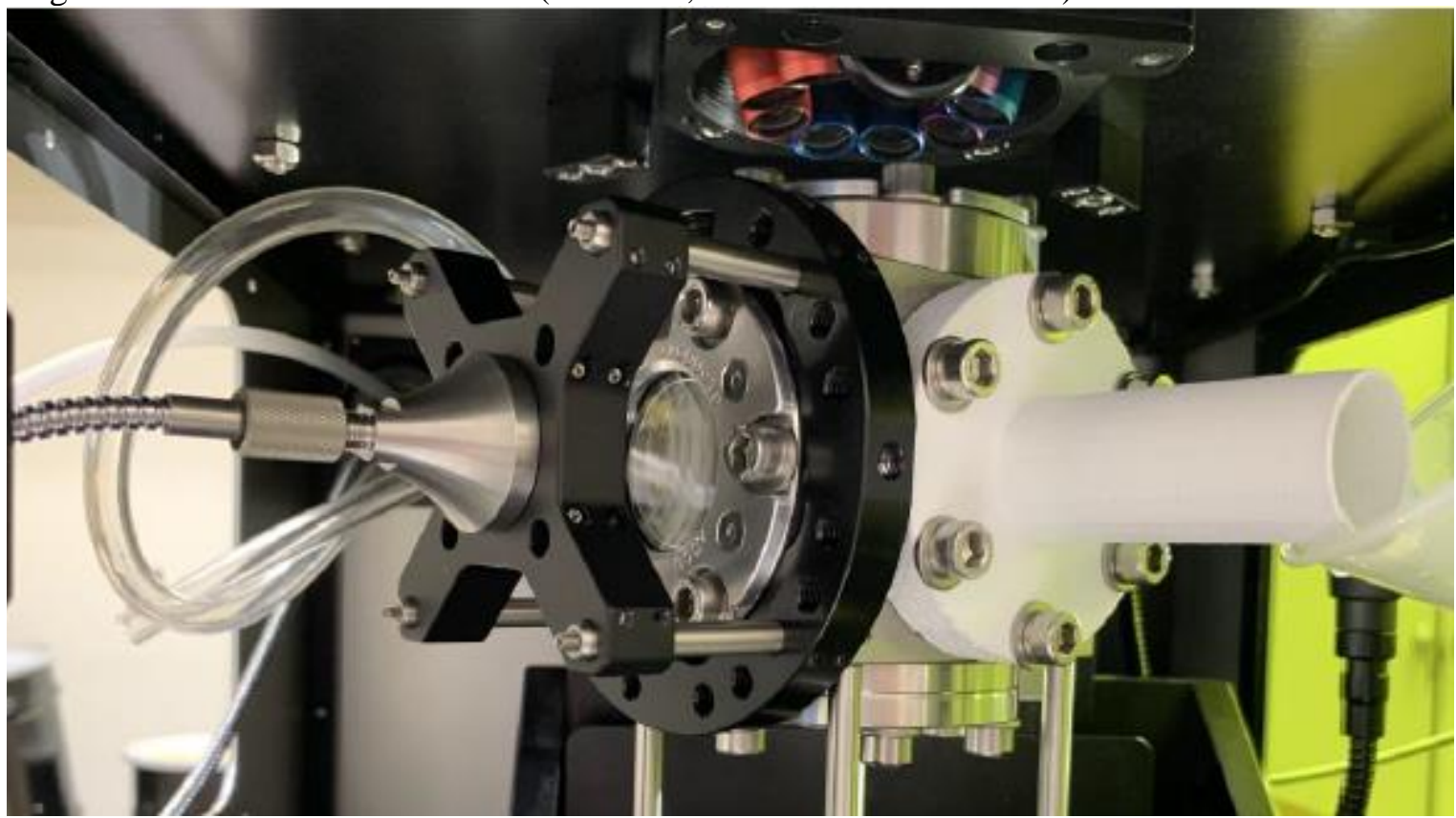

Figure 16. A photo of the LIBS prototype system coupled to the aerosol generator. Figure reproduced courtesy of (Myhre, et al. 2019).

Gas-based detectors have intrinsic gamma-ray discrimination, are rugged, have a large range of form factors, and resist radiation damage. Scintillator technology is commonly avoided because of the gammaray and photomultiplier sensitivity to incident radiation. Solid-state detectors are avoided because they are very susceptible to neutron damage. The reactor's reactivity is monitored through the detection of neutron flux because this is equivalent to the fission rate and consequently the heat produced (i.e., the operating power). The detectors are placed inside or outside the core. Pressurized water reactor neutron flux monitor instrumentation can be placed inside and outside the pressure vessel. The typical neutron flux is $10^{11} \mathrm{n} \cdot \mathrm{cm}^{-2} \cdot \mathrm{s}^{-1}$ and the gamma field is $10^{6} \mathrm{R} \cdot \mathrm{h}^{-1}$ with temperatures reaching $100{ }^{\circ} \mathrm{C}$. Boiling water reactor instrumentation is placed in the core itself and subsequently, the incident radiation exposure is larger neutron flux is $10^{13} \mathrm{n} \cdot \mathrm{cm}^{-2} \cdot \mathrm{s}^{-1}$, and the gamma field is $10^{8} \mathrm{R} \cdot \mathrm{h}^{-1}$ with temperatures reaching $300{ }^{\circ} \mathrm{C}$ and pressures up to 2,500 psi (Knoll 2000). Examples of in-core power level monitors are the fission chamber and the self-powered neutron detector. Fission chambers are gas detectors of cylindrical design with coaxial electrodes. A lining of fissile and/or fertile material (e.g., ${ }^{234} \mathrm{U}$ and $\left.{ }^{235} \mathrm{U}\right)$ acts as the neutron convertor material. Detection takes place by measuring the charge produced from ionization of the gas filled chamber by the fission fragments. Fission chambers can be developed to operate in various magnitudes of radiation fields and can be made small enough to be used in the core of a reactor. Another type of gas-based detector is the self-powered neutron detector. This type of gas detector also relies on a conversion material (i.e., an emitter) for the capture of neutrons. The material used has a high capture cross section, and the activation product subsequently beta decays. The beta decay current is measured directly, and there is no need of high voltage application, providing the basis for the name "selfpowered." However, these detectors have a slow response time because of the half-life of the resulting activated nuclide. Self-powered neutron detectors can also be constructed to detect electrons from gamma decay. These detectors rely on the measurement of the current produced from secondary electrons following prompt gamma rays resulting from neutron capture in the emitter. Application of either of these detector technologies will require careful attention to material and construction design. In addition, an evaluation of the expected environmental radiation fields and temperature are also needed. 


\subsubsection{Instrumentation and Technical Gaps}

Excluding HKED and certain process instrumentation for LWRs, none of the described technologies are available as commercially off-the-shelf (COTS) instrumentation. Therefore, in addition to R\&D to develop and increase the technical readiness level (TRL), significant stringent testing and demonstrations will be required to validate and verify the utility of each technology. These tests will include in-field measurements with realistic high-temperature, high-radiation, and corrosive environments (i.e., TRL 6 (U.S Department of Energy 2011)). Robustness and long-term reliability of these technologies must be evaluated. The ease of use including maintenance/replacement under harsh conditions will also need to be considered. In support of these test, suitable test beds - which have pumped, flowing fuel salt, and the associated radiation field, need to be identified and/or developed. It is imperative that the fuel salt loops, and radiation fields are used to evaluate all technology being considered for in-field MSR measurements to evaluate the hardiness and longevity of the sensor and electronics. This is especially true for proposed technology where it is not trivial to locate the supporting electronics at a large standoff distance outside of the high radiation environment.

The instrumentation included in this report was evaluated for certain criteria to generalize their applicability to MSR measurements. The instrumentation was ranked on TRL, if testing in a molten salt environment had been made, and the utility to safeguards measurements as shown in Table 4.

There are additional technologies not considered here that may also be needed to meet other measurement tasks. Some examples of these measurements are assay of tritium beds, measuring protactinium if separated in the thorium fuel cycle, and other special inventory materials. The potential for joint use equipment also needs to be explored. This could be very useful as MSR vendors make their plans available for instrumentation and control. 
Table 4. Radiometric instrumentation and technology reviewed for applicability to MSR implementation and safeguards measurements.

\begin{tabular}{|c|c|c|c|c|c|c|}
\hline Technology & Measurement & $\begin{array}{l}\text { Detection } \\
\text { Basis }\end{array}$ & TRL & $\begin{array}{c}\text { Molten } \\
\text { Salt } \\
\text { Tested }\end{array}$ & $\begin{array}{l}\text { Radioactive } \\
\text { Salt Tested }\end{array}$ & $\begin{array}{c}\text { Safeguards } \\
\text { Utility }\end{array}$ \\
\hline $\begin{array}{l}\text { High-Dose } \\
\text { Neutron Detector } \\
\text { (HDND) }\end{array}$ & $\begin{array}{l}\text { Radiometric - } \\
\text { neutron }\end{array}$ & $\begin{array}{l}\text { Moderation and } \\
{ }^{3} \text { He tubes }\end{array}$ & $4-5$ & $\mathrm{~N}$ & $\mathrm{~N}^{2}$ & $\mathrm{M}$ \\
\hline $\begin{array}{l}\text { Online Actinide } \\
\text { Sensor }\end{array}$ & $\begin{array}{l}\text { Actinide } \\
\text { concentration }\end{array}$ & $\begin{array}{l}\text { Voltage applied } \\
\text { to electrode }\end{array}$ & 3 & $\mathrm{Y}$ & $\mathrm{N}$ & $\mathrm{M}$ \\
\hline $\begin{array}{l}\text { In Situ Actinide } \\
\text { Monitor }\end{array}$ & $\begin{array}{l}\text { Actinide } \\
\text { mass/composition }\end{array}$ & $\begin{array}{l}\text { Measurement } \\
\text { of melting point } \\
\text { (temperature) }\end{array}$ & $2-3$ & $\mathrm{~N}$ & $\mathrm{~N}^{3}$ & $\mathrm{M}$ \\
\hline $\begin{array}{l}\text { Wide Bandgap } \\
\text { Alpha Detector }\end{array}$ & $\begin{array}{l}\text { Radiometric - } \\
\text { alpha } \\
\text { spectroscopy }\end{array}$ & $\begin{array}{l}\text { Semiconductor } \\
\text { charge } \\
\text { collection }\end{array}$ & 3 & $\mathrm{Y}$ & $\mathrm{N}^{4}$ & $\mathrm{~L}$ \\
\hline Microcalorimeter & $\begin{array}{l}\text { Radiometric- } \\
\text { photon } \\
\text { spectroscopy }\end{array}$ & $\begin{array}{l}\text { Induced heat } \\
\text { from incident } \\
\text { radiation }\end{array}$ & $4-5$ & $\mathrm{~N}$ & $\mathrm{~N}^{5}$ & $\mathrm{M}$ \\
\hline Triple Bubbler & $\begin{array}{l}\text { Salt density and } \\
\text { depth }\end{array}$ & $\begin{array}{l}\mathrm{I}-\mathrm{V} \text { curves of } \\
\text { independent } \\
\text { probes }\end{array}$ & $2-3$ & $\mathrm{Y}$ & $\mathrm{N}$ & $\mathrm{M}$ \\
\hline Voltammetry & $\begin{array}{l}\text { Salt composition } \\
\text { (molecular) }\end{array}$ & $\begin{array}{l}\text { I-V curve w/ } \\
\text { electrode }\end{array}$ & $2-3$ & $\mathrm{Y}$ & $\mathrm{N}$ & $\mathrm{M}$ \\
\hline $\begin{array}{l}\text { High-Throughput } \\
\text { Micro-Sampling }\end{array}$ & $\begin{array}{l}\text { Direct salt } \\
\text { sampling }\end{array}$ & $\begin{array}{l}\text { Pneumatic salt } \\
\text { droplet }\end{array}$ & $2-3$ & $\mathrm{Y}$ & $\mathrm{N}$ & M \\
\hline $\begin{array}{l}\text { Hybrid K-Edge } \\
\text { Densitometer } \\
\text { (HKED) }\end{array}$ & $\begin{array}{l}\text { Radiometric - U } \\
\text { and Pu } \\
\text { concentrations in } \\
\text { samples }\end{array}$ & $\begin{array}{l}\text { K-Edge } \\
\text { transmission } \\
\text { and } \mathrm{x} \text {-ray } \\
\text { fluorescence } \\
\end{array}$ & 9 (COTS) & $\mathrm{N}$ & $\mathrm{N}^{6}$ & $\mathrm{M}$ \\
\hline Fission Chamber ${ }^{7}$ & $\begin{array}{l}\text { Radiometric - } \\
\text { neutron }\end{array}$ & $\begin{array}{l}\text { Gas-based } \\
\text { charge } \\
\text { measurement }\end{array}$ & 9 (COTS) & $\mathrm{N}$ & $\mathrm{N}^{8}$ & $\mathrm{M}$ \\
\hline $\begin{array}{l}\text { In-core, Ex-core, } \\
\text { and self-powered } \\
\text { Neutron Detectors }\end{array}$ & $\begin{array}{l}\text { Radiometric - } \\
\text { neutron }\end{array}$ & $\begin{array}{l}\text { Gas-based } \\
\text { charge } \\
\text { measurement }\end{array}$ & 9 (COTS) & $\mathrm{N}$ & $\mathrm{N}^{10}$ & $\mathrm{M}$ \\
\hline
\end{tabular}

\footnotetext{
${ }^{2}$ Instrument field tested with spent fuel rods; gamma dose rates are orders of magnitude less than what is expected at an MSR. Possible implementation of the miniature HDND version.

${ }^{3}$ Measurements have been made in molten U-Pu but not in molten salt or with radioactive molten salt mixtures.

${ }^{4}$ An electroplating procedure places the test material in contact with the sensor. Testing was performed in molten salt ( $\mathrm{LiCl}-$

$\mathrm{KCl}-\mathrm{UCl}_{3}-\mathrm{ThCl}_{4}$ ) and only $\mathrm{U}$ was plated on the detector. It is unclear how the sensor would react with the expected activity and host of isotopes present in a molten salt from a reactor loop.

${ }^{5}$ Field campaigns performed, but no direct measurements of highly radioactive material are reported. Dead time and recovery would need to be understood.

${ }^{6}$ The instrument is deployed in reprocessing fuel reprocessing facilities. Testing is required to understand the instrument response to molten from a reactor loop.

${ }^{7}$ Example manufacturers are Photonis and Rolls-Royce.

${ }^{8}$ These instruments are used in LWR. Testing and simulations are required to understand the instrument response to an MSR.

${ }^{9}$ Example manufacturers are Photonis and Rolls-Royce.

${ }^{10}$ These instruments are used in LWR. Testing and simulations are required to understand the instrument response to an MSR.
} 


\section{SAFEGUARDS DESIGN APPROACH FOR MSR}

The ability to monitor and perform measurements during operation of an MSR is a severe technical challenge due to the harsh environmental conditions. This includes excessive temperatures and intense radiation fields. Material balance area placement and overall definition of that boundary in a (commercial) MSR will vary depending on design and the developed NMAC plan. To perform measurements for safeguards in support of material control and monitoring an assessment strategy has been illustrated that can be tailored to specific vendor designs as design information becomes available

\section{FUTURE WORK AND CONCLUSIONS}

The modeling and simulation capabilities developed in FY19 have allowed a general understanding of the 5\% enriched U thermal MSDR fuel cycle. The SCALE/TRITON and TRANSFORM tools each have methods to investigate changes in the liquid fuel by removing groups of elements to model the envisioned/necessary fission product extraction for both liquid and gaseous refining mechanisms. A parametric analysis using SCALE of the MSDR under low power density for an extended reactor cycle of greater than 9 years demonstrated the coupling of reactor operations (i.e., power and temperature) and reactor materials (i.e., graphite density) to nuclide transmutation and/or production. The correlation heat map of the parameters (y-axis) and observables (x-axis) is given in Figure 5. These correlations are useful because slight changes in reactor operations within the uncertainties associated with instrumental controls (e.g., temperature measurements) and structural material characteristics (e.g., graphite density) can produce significant changes to (potential) nuclide signatures that are of interest to safeguards. A model based on the Modelica language was developed (i.e., TRANSFORM), based on point kinetics to simulate the MSDR. The (time) dynamic, transient behavior of the MSDR model was investigated by three scenarios that varied in the input driver (i.e., how the fuel salt was removed/added) and if reactivity control was inserted in the model. The reactivity, total power, and ${ }^{135} \mathrm{Xe}$ production were analyzed in relation to these scenarios. This analysis provided a means to observe the tight coupling between the fuel salt and potential observables, but it is unlikely that these conditions/scenarios would be "normal" operations for a commercial MSR — operation without reactivity control.

The modeling tools will be utilized to identify and understand other correlations of fission products and actinides throughout the fuel cycle of an MSR as potential signatures for a safeguards approach. The MSRE gamma spectroscopy measurements will be used as a starting point for this work as these were direct measurements of fission product mobility in the system - albeit measured for the Th fuel cycle. In addition to identifying the observable radiometric signatures, the dose and temperature environmental parameters will be determined. Combining these pieces of information is necessary to develop a robust and comprehensive (safeguards) monitoring approach.

The follow-on studies will leverage the modeling tools as developed specifically for MSRs. In particular, the tools can be benchmarked against the direct measurements performed on the MSRE using other available software (e.g., GADRAS) to understand detector response. Once benchmarked, studies will be performed to tabulate fission product signatures and how they relate to the isotopic variations of the fissile material as the fuel is consumed. Then, optimum measurement locations can be identified with the system-level modeling available with TRANSFORM. Next, a safeguards plan can be derived and extended to design specific, commercial, next generation MSRs. 


\section{REFERENCES}

Bae, J. W., B. R. Betzler, and A. Worrall. 2019. Molten Salt Reactor Neutronic and Fuel Cycle Sensitivity and Uncertainty Analysis. ORNL. doi:10.2172/1456790.

Bettis, E. S., L. G. Alexander, and H. L. Watts. 1972. Design Studies of a Molten-Salt Reactor Demonstration Plant. ORNL.

Betzler, B. R., J. J. Powers, and A. Worrall. 2017. "Molten Salt Reactor Neutronics and Fuel Cycle Modeling and Simulation with SCALE." Ann. Nucl. Energy (Elsevier) 101: 489--503. doi:10.1016/j.anucene.2016.11.040.

Burr, T., K. Budlong-Sylvester, K. Myers, S. Demuth, A. Bakel, J. Krebs, S. Bryan, et al. 2012. "Roles for Process Monitoring in Nuclear Safeguards at Aqueous Reprocessing Plants." Journal of Nuclear Materials Management.

Forum, GEN IV International. 2018. GIF R\&D Outlook for Generation IV Nuclear Energy Systems: 2018 Update. GIF. www.gen-4.org.

Greenwood, M. S., and B. R. Betzler. 2018. "Modified Point-Kinetics Model for Neutron Precursors and Fission Product Behavior for a Fluid-Fueled Molten Salt Reactor." Nucl. Sci. Eng. 193. doi:10.1080/00295639.2018.1531619.

Greenwood, M. Scott, Benjamin R. Betzler, A. Lou Qualls, Junsoo Yoo, and Cristian Rabiti. 2020. "Demonstration of the Advanced Dynamic System Modeling Tool TRANSFORM in a Molten Salt Reactor Application via a Model of the Molten Salt Demonstration Reactor." Nuclear Technology 206 (3). doi:10.1080/00295450.2019.1627124.

Greenwood, Michael Scott, Benjamin R. Betzler, and A. L. Qualls. 2018. Dynamic System Models for Informing Licensing and Safeguards Investigations of Molten Salt Reactors. ORNL. doi:10.2172/1456790.

Harrer, Joseph M., and James G. Beckerley. 1973. Nuclear Power Reactor Instrumentation Systems Handbook. Vol. I. II vols. Office of Information Services U.S. Atomic Energy Commission.

Holcomb, David E., Roger A. Kisner, and Sacit M. Cetiner. 2018. Instrumentation Framework for Molten Salt Reactors. ORNL/TM-2018/868.

Houtzeel, A., and F. F. Dyer. 1972. A Study of Fission Products in the Molten-Salt Reactor Experiment by Gamma Spectrometry. ORNL-TM-3151.

International Atomic Energy Agency. 2016. IAEA Bulletin: Preventing the Spread of Nuclear Weapons. IAEA.

International Atomic Energy Agency. 2001. International Atomic Energy Agency Safeguards Glossary. Vienna: IAEA.

International Atomic Energy Agency. 2014. International Safeguards in the Design of Nuclear Reactors. NP-T-2.9, Vienna: IAEA.

Knoll, Glenn F. 2000. Radiation Detection and Measurement. John Wiley \& Sons Inc.

Mirion (Canberra). n.d. International Nuclear Safeguards Solutions. Canberra. www.mirion.com.

Myhre, Kristian, Joanna McFarlane, Guillermo Del Cul, N. Dianne Ezell, and Hunter Andrews. 2019. "Molten Salt Reactor Off-gas Monitoring using Laser Induced Breakdown Spectroscopy." ACS National Meeting.

Robertson, R. C. 1971. Conceptual Design of a Single-Fluid Molten-Salt Breeder Reactor. ORNL-4541.

Robertson, R. C. 1965. MSRE Design and Operations Report Part I. ORNL-TM-0728. doi:10.2172/4654707.

U.S Department of Energy. 2011. Technology Readiness Assessment Guide. DOE G 413.3-4.

U.S. Nuclear Regulatory Commission. 2019. Non-Light-Water Reactor Implementation Action Plan Progress Summary and Future Plans. U.S. Nuclear Regulatory Commission ML1834.

W. A. Wieselquist, R. A. Lefebvre, and M. A. Jessee, Eds.,. 2020. SCALE Code System. ORNL/TM2005/39, ORNL. 
Worrall, A., J. W. Bae, B. R. Betzler, M. S. Greenwood, and L. G. Worrall. 2019. Molten Salt Reactor Safeguards: The Necessity of Advanced Modeling and Simulations to Inform on Fundamental Signatures. Proceedings from 60th INMM Meeting, INMM. 